\title{
Status Report on
} Development of TREAT Water Loop

Nuclear Technology

Research and Development

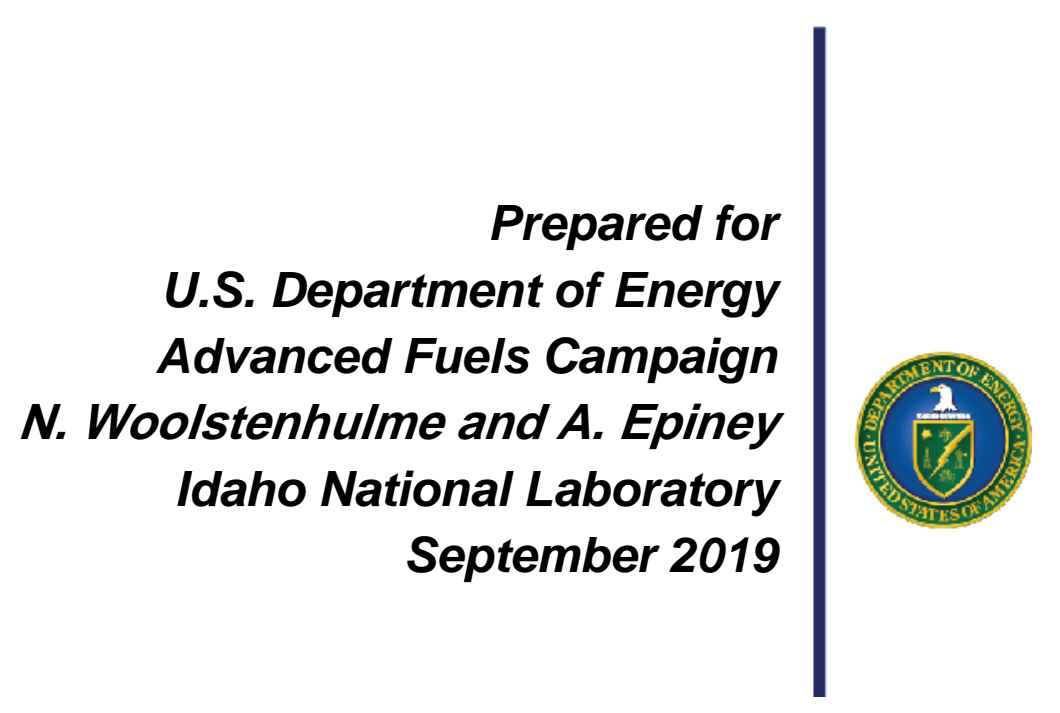




\section{DISCLAIMER}

This information was prepared as an account of work sponsored by an agency of the U.S. Government. Neither the U.S. Government nor any agency thereof, nor any of their employees, makes any warranty, expressed or implied, or assumes any legal liability or responsibility for the accuracy, completeness, or usefulness, of any information, apparatus, product, or process disclosed, or represents that its use would not infringe privately owned rights. References herein to any specific commercial product, process, or service by trade name, trade mark, manufacturer, or otherwise, does not necessarily constitute or imply its endorsement, recommendation, or favoring by the U.S. Government or any agency thereof. The views and opinions of authors expressed herein do not necessarily state or reflect those of the U.S. Government or any agency thereof. 


\section{SUMMARY}

The Transient Reactor Test (TREAT) facility is a transient test reactor which resumed operations in 2017 to support safety research on advanced nuclear fuels. Upon resuming operations, TREAT successfully demonstrated its capability as a transient neutron source for fuel safety research on light water-cooled fuel systems, and efforts have been underway to establish water-environment capabilities for testing specimens. Static water capsule capabilities are becoming established at TREAT to support single rod testing. The capsule approach is appropriate for cost-effective experiments or when important test variables are well enough understood to be precisely targeted, but, due to lack of forced convection, cannot achieve all desired temperature distribution histories in the test fuel, provide representative timing in water phase transitions, nor provide hydraulic conditions for multi-rod bundle testing. For these reasons, design and development has been undertaken for the TREAT Water-Environment Recirculating Loop (TWERL). A compact self-contained loop design was selected previously based on its adequacy for supporting brief overpower transients. Based on an emerging focus within accident tolerant fuel development projects, specifically toward depressurization/undercooling phenomena in zirconium alloy-clad fuel systems, the present effort undertook an engineering trade study to determine whether this self-contained concept was still appropriate. Thermal hydraulic modeling showed reasonable comparison between commercial plants, the self-contained TWERL concept, and a candidate facility-scale TWERL concept. Hydraulic predictions showed that the central rod within a 5-rod X-shaped bundle would be within the hydraulic limitations of a compact pump. A supplier of custom water pumps provided high confidence in such a pump through engineering efforts. Based on the design requirements developed for TWERL, it was determined that the original selection of a compact self-contained loop remained valid and well-placed for programmatic needs. More than just reaffirming a prior decision, however, these efforts cultivated models for accelerating future design efforts, identified design parameters able to affect a more capable system, and identified a viable supplier for the crucial compact water pump. 
INTENTIONALLY BLANK 


\section{CONTENTS}

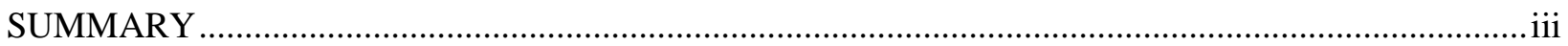

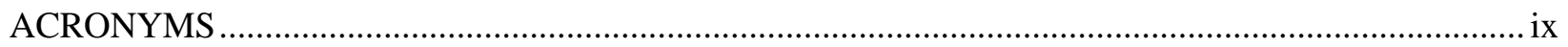

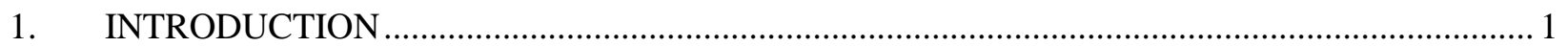

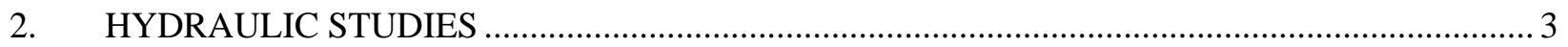

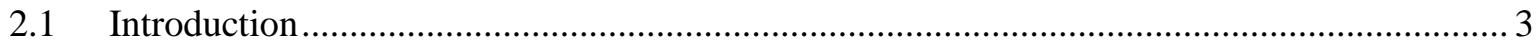

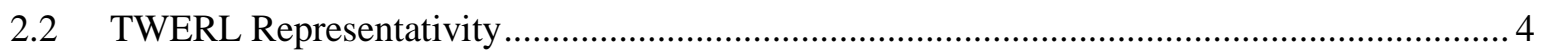

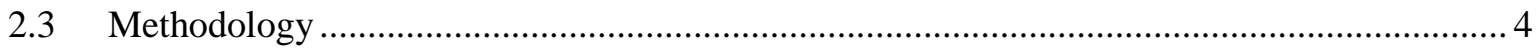

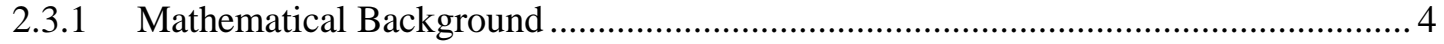

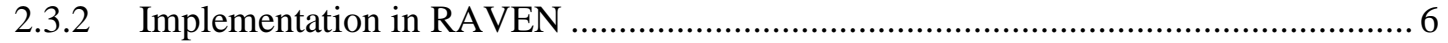

2.4 Application of "Representativity” to TWERL LOCA Transient .......................................... 7

2.4.1 Model Description: Representative 3-loop Westinghouse PWR ................................ 8

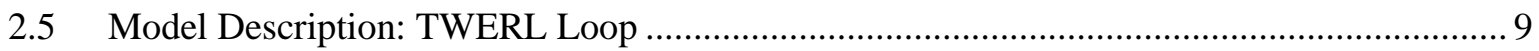

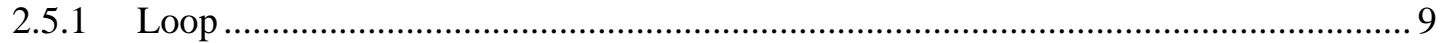

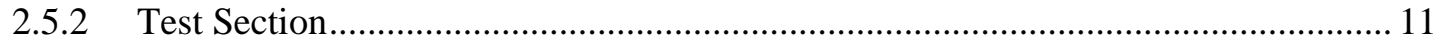

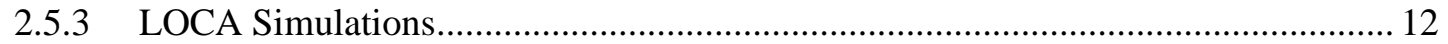

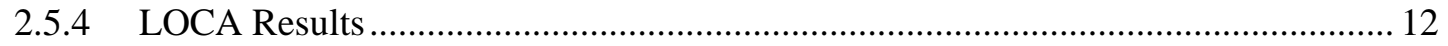

2.5.5 Representativity and Prototypicality Conclusions .................................................... 22

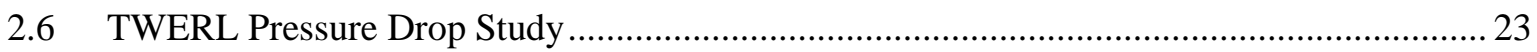

2.6.1 Boundary and Operating Conditions and Assumptions .......................................... 23

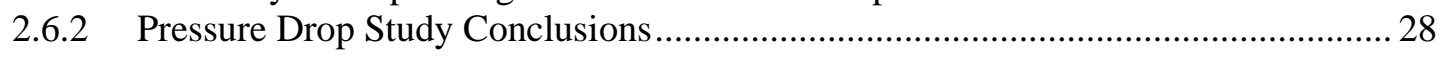

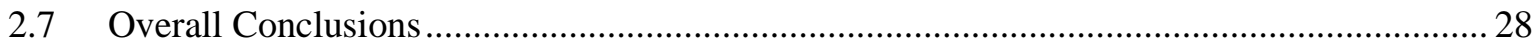

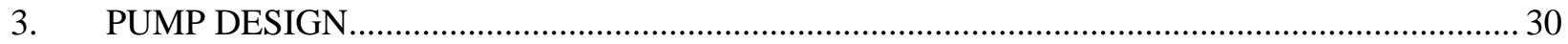

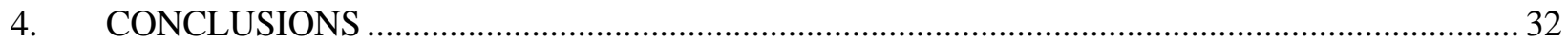

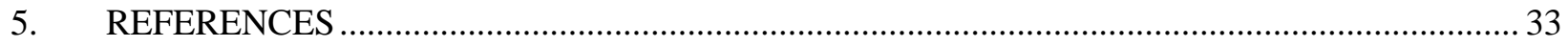

\section{FIGURES}

Figure 1. Left: TWERL loop system concept; Right: TWERL self-contained concept. ............................. 3

Figure 2. RAVEN workflow for experiment design optimization using experiment

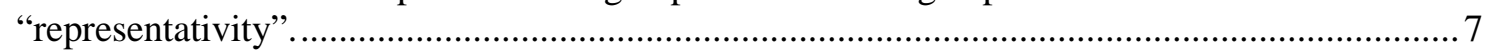

Figure 3. RELAP5-3D model of a typical PWR: vessel and primary coolant loop................................... 9

Figure 4. RELAP5-3D model of a typical PWR: secondary coolant loop................................................ 9

Figure 5. REALP5-3D model of the TWERL loop. ............................................................................. 10

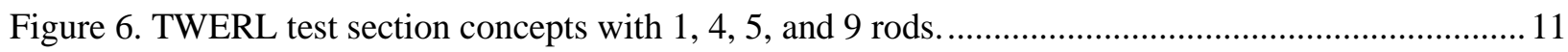

Figure 7. Pressure evolution for TWERL LOCA compared to PWR large break LOCA (1 rod test section design). Left: 300 second transient. Right: Zoom of first 25 seconds of transient. 
Figure 8. PCT for 1 rod design, 1 bar back-up pressure, 100MW TREAT heating power and $4.5 \mathrm{~m} / \mathrm{s}$ coolant velocity. Left: 300 second transient with representativity on right side axis. Right: Zoom of first 25 seconds of transient.

Figure 9. PCT for 1 rod design, 1 bar back-up pressure, 100MW TREAT heating power and $5.5 \mathrm{~m} / \mathrm{s}$ coolant velocity. Left: 300 second transient with representativity on right side axis. Right: Zoom of first 25 seconds of transient. 14

Figure 10. PCT for 1 rod design, 1 bar back-up pressure, 500MW TREAT heating power and $4.5 \mathrm{~m} / \mathrm{s}$ coolant velocity. Left: 300 second transient with representativity on right side axis. Right: Zoom of first 25 seconds of transient. 14

Figure 11. PCT for 1 rod design, 1 bar back-up pressure, 500MW TREAT heating power and $5.5 \mathrm{~m} / \mathrm{s}$ coolant velocity. Left: 300 second transient with representativity on right side axis. Right: Zoom of first 25 seconds of transient.

Figure 12. PCT for 1 rod design, 10 bar back-up pressure, 100MW TREAT heating power and $4.5 \mathrm{~m} / \mathrm{s}$ coolant velocity. Left: 300 second transient with representativity on right side axis. Right: Zoom of first 25 seconds of transient.

Figure 13. PCT for 1 rod design, 10 bar back-up pressure, 100MW TREAT heating power and $5.5 \mathrm{~m} / \mathrm{s}$ coolant velocity. Left: 300 second transient with representativity on right side axis. Right: Zoom of first 25 seconds of transient.

Figure 14. PCT for 1 rod design, 10 bar back-up pressure, 500MW TREAT heating power and $4.5 \mathrm{~m} / \mathrm{s}$ coolant velocity. Left: 300 second transient with representativity on right side axis. Right: Zoom of first 25 seconds of transient. 16

Figure 15. PCT for 1 rod design, 10 bar back-up pressure, 500MW TREAT heating power and $5.5 \mathrm{~m} / \mathrm{s}$ coolant velocity. Left: 300 second transient with representativity on right side axis. Right: Zoom of first 25 seconds of transient. 16

Figure 16. PCT for 4 rod design, 1 bar back-up pressure, 100MW TREAT heating power and $4.5 \mathrm{~m} / \mathrm{s}$ coolant velocity. Left: 300 second transient with representativity on right side axis. Right: Zoom of first 25 seconds of transient.

Figure 17. PCT for 4 rod design, 10 bar back-up pressure, 100MW TREAT heating power and $4.5 \mathrm{~m} / \mathrm{s}$ coolant velocity. Left: 300 second transient with representativity on right side axis. Right: Zoom of first 25 seconds of transient.

Figure 18. PCT for 5 rod design, 1 bar back-up pressure, 100MW TREAT heating power and $4.5 \mathrm{~m} / \mathrm{s}$ coolant velocity. Left: 300 second transient with representativity on right side axis. Right: Zoom of first 25 seconds of transient.

Figure 19. PCT for 5 rod design, 10 bar back-up pressure, 100MW TREAT heating power and $4.5 \mathrm{~m} / \mathrm{s}$ coolant velocity. Left: 300 second transient with representativity on right side axis. Right: Zoom of first 25 seconds of transient. 18

Figure 20. PCT for 9 rod design, 1 bar back-up pressure, 100MW TREAT heating power and $4.5 \mathrm{~m} / \mathrm{s}$ coolant velocity. Left: 300 second transient with representativity on right side axis. Right: Zoom of first 25 seconds of transient. 18

Figure 21. PCT for 9 rod design, 10 bar back-up pressure, 100MW TREAT heating power and $4.5 \mathrm{~m} / \mathrm{s}$ coolant velocity. Left: 300 second transient with representativity on right side axis. Right: Zoom of first 25 seconds of transient. 
Figure 22. Maximum cladding to center line fuel temperature for 1 rod design, 1 bar back-up pressure, 100MW TREAT heating power and $4.5 \mathrm{~m} / \mathrm{s}$ coolant velocity. Left: 300 second transient with representativity on right side axis. Right: Zoom of first 25 seconds of transient.

Figure 23. Maximum cladding to center line fuel temperature for 1 rod design, 10 bar back-up pressure, 100MW TREAT heating power and $4.5 \mathrm{~m} / \mathrm{s}$ coolant velocity. Left: 300 second transient with representativity on right side axis. Right: Zoom of first 25 seconds of transient.

Figure 24. Maximum cladding to center line fuel temperature for 4 rod design, 1 bar back-up pressure, 100MW TREAT heating power and $4.5 \mathrm{~m} / \mathrm{s}$ coolant velocity. Left: 300 second transient with representativity on right side axis. Right: Zoom of first 25 seconds of transient.

Figure 25. Maximum cladding to center line fuel temperature for 4 rod design, 10 bar back-up pressure, 100MW TREAT heating power and $4.5 \mathrm{~m} / \mathrm{s}$ coolant velocity. Left: 300 second transient with representativity on right side axis. Right: Zoom of first 25 seconds of transient.

Figure 26. Maximum cladding to center line fuel temperature for 5 rod design, 1 bar back-up pressure, 100MW TREAT heating power and $4.5 \mathrm{~m} / \mathrm{s}$ coolant velocity. Left: 300 second transient with representativity on right side axis. Right: Zoom of first 25 seconds of transient.

Figure 27. Maximum cladding to center line fuel temperature for 5 rod design, 10 bar back-up pressure, 100MW TREAT heating power and $4.5 \mathrm{~m} / \mathrm{s}$ coolant velocity. Left: 300 second transient with representativity on right side axis. Right: Zoom of first 25 seconds of transient.

Figure 28. Maximum cladding to center line fuel temperature for 9 rod design, 1 bar back-up pressure, 100MW TREAT heating power and $4.5 \mathrm{~m} / \mathrm{s}$ coolant velocity. Left: 300 second transient with representativity on right side axis. Right: Zoom of first 25 seconds of transient.

Figure 29. Maximum cladding to center line fuel temperature for 9 rod design, 10 bar back-up pressure, 100MW TREAT heating power and $4.5 \mathrm{~m} / \mathrm{s}$ coolant velocity. Left: 300 second transient with representativity on right side axis. Right: Zoom of first 25 seconds of transient. 21

Figure 30. No heat exchanger, volumetric flow rate vs. loop pressure drop. ........................................... 25

Figure 31. No heat exchanger, volumetric flow rate vs. pump head. ........................................................ 26

Figure 32. Simple heat exchanger, volumetric flow rate vs. loop pressure drop..................................... 26

Figure 33. Simple heat exchanger, volumetric flow rate vs. pump head. ............................................... 27

Figure 34. More heat exchanger pressure drop, volumetric flow rate vs. loop pressure drop................... 27

Figure 35. More heat exchanger pressure drop, volumetric flow rate vs. pump head............................... 28

Figure 36. Pump Dimensional Envelope (dimensions in inches). ..........................................................30

Figure 37. Preliminary Renderings of Compact Canned Motor Pump..................................................... 32 


\section{TABLES}

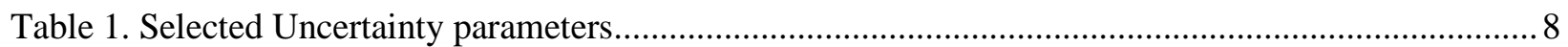

Table 2. Test section characteristics for different TWERL designs ....................................................... 11

Table 3. Representative commercial plant steady state conditions.......................................................... 12

Table 4. Volumetric flow and mass flow for selected fluid velocities in the different TWERL test

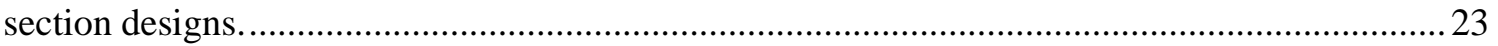

Table 5. Simple heat exchanger designs for the different TWERL test section designs. ...........................24 
ACRONYMS

ASME American Society of Mechanical Engineers

ATF Accident Tolerant Fuels

ATR Advanced Test Reactor

ECCS Emergency Core Cooling System

FOM Figure of Merit

HX Heat Exchanger

INL Idaho National Laboratory

LMTD Log Mean Temperature Difference

LOCA Loss of Coolant Accident

LWR Light Water Reactor

MaxCtoF Maximum Cladding to Center line Fuel

PCF Power Coupling Factor

PCT Peak Cladding Temperature

PWR Pressurized Water Reactor

RIA ReactivityInitiated Accident

SL tube row pitch

ST tube pitch

TREAT Transient Reactor Test (facility)

TWERL TREAT Water-Environment Recirculating Loop

UAM Uncertainty Analysis in Modeling

VFD variable frequency drive 
INTENTIONALLY BLANK 


\section{STATUS REPORT ON DEVELOPMENT OF TREAT WATER LOOP}

\section{INTRODUCTION}

The Transient Reactor Test (TREAT) facility is a graphite-based transient test reactor at the Idaho National Laboratory (INL). TREAT started operation in 1959 and performed thousands of transient irradiations for the primary purpose of nuclear fuel safety research. TREAT operations were suspended in 1994, and then, several years later, resumed reactor operations in 2017 to support development of advanced nuclear fuels. TREAT's more recent historic focus had been for transients with relevance to sodium-cooled fast spectrum reactors. TREAT's first year of modern experiment work performed in 2018, however, saw the demonstration of new kinds of transients focused on light water reactor (LWR) needs, including reactivity-initiated accidents (RIA) and loss-of-coolant accidents (LOCA). The successful outcome of these efforts confirmed TREAT's viability as a transient neutron source for LWR safety research.

Since TREAT's core is air cooled and provides no "built-in" thermal hydraulic boundary conditions for tests specimens, efforts have been underway to establish water-environment capabilities for testing specimens. Small static water capsules have been established to support single rod RIA testing where transient heating is brief. Similarly, deployment of enhanced water capsules with blowdown capability is nearing completion to support single rod LOCA testing. With careful experiment design, these capsules can provide representative temperature response histories and water phase transitions for some experiment parameters. The capsule approach is appropriate for cost-effective early phase phenomena identification studies on novel fuels, or when the important test variables are thought to be fairly well understood so that they can be precisely targeted (such as they are for current fleet fuels with moderate burnup $\mathrm{UO}_{2}$ in uncoated zirconium alloy cladding). Due to lack of forced convection, however, the capsule approach cannot achieve representative temperature histories in all regions of the test fuel simultaneously (e.g., cladding and fuel centerline temperatures) while providing representative timing in water phase transitions. Also, the capsule approach cannot provide appropriate hydraulic conditions for multi-rod bundle testing. For these reasons, design and development has been undertaken for the TREAT Water-Environment Recirculating Loop (TWERL).

The TWERL capability will enable highly-prototypic testing of LWR fuel rods and small bundles for novel fuel designs (when performance phenomena are not well known) or for so-called "capstone tests" which support licensing of mature fuel designs at their full capability envelope with little risk for performance biasing due to thermal hydraulic artifacts. A unique water loop design, where a compact self-contained pump and piping weldment were packaged entirely within a cask-transportable enclosure, was selected in conceptual design efforts performed previously [1]. This concept had been selected earlier in the development program for Accident Tolerant Fuels (ATF) when many of the candidate cladding types were projected to have extraordinary tolerance to undercooling (e.g., LOCA), but where performance under rapid overheating (e.g., RIA) was largely unknown. The original self-contained TWERL design concept was focused toward RIA testing and valued for its simplicity in controlling radiologic hazards. With the recent emergence of ATF focus on coated zirconium alloy cladding and its potential to support increased enrichment/burnup LWR licenses by mitigating the impacts of LOCA phenomena (e.g., fuel fragmentation, cladding ballooning), it was appropriate to revisit the TWERL design concept selection to ensure that it could support undercooling and bundle-testing conditions as well. 
The present report describes an engineering trade study performed in fiscal year 2019 to compare the self-contained TWERL concept to a more conventional facility-scale water loop. The facility scale loop is a more expensive option (both in deployment cost and test schedule) due to its sizeable hydraulic support equipment (e.g., pump, pressurizer, heat exchangers) residing outside of the reactor's shielding. The facility-scale system also requires systems for contamination control during removal of the in-pile portion(s), coolant debris filtering, and fission product cleanup for loop reuse. Despite these drawbacks, the facility-scale system may be needed to provide thermal hydraulic conditions for ATF-focused and/or bundle testing needs. Additionally, recent experiences with other projects, but pertaining to custom compact water pumps, gave impetus to reevaluate the viability of supply for pumps supporting the self-contained TWERL concept. As a result of other previous work [2], it had been shown that TREAT could drive adequate nuclear heating for LOCA simulation in small bundles of high burnup LWR fuel, so the present studies did not include any new neutronics calculations. Rather, three main areas were addressed under the present studies as follows:

1. The first effort addressed hydraulic system design and modeling of the two TWERL concepts for a variety of scenarios with numerical comparison to LWR plant response.

2. The second effort entailed subcontract work with a potential pump vendor to determine whether the compact self-contained concept was viable.

3. The third effort included the creation and approval of formal engineering design requirements for future TWERL detailed engineering efforts. 


\section{HYDRAULIC STUDIES}

\subsection{Introduction}

The TWERL is currently in its pre-design phase at INL. A first question to answer is if the TWERL loop can be realized as a "self-contained" loop where the whole assembly (including pump, heat exchanger [HX], and other components) will fit in the experiment opening of the TREAT reactor, or if the design has to be a "loop system concept" where only the test section is inserted in the TREAT core while the other components (HX, pump, pressurizer, etc.) are located outside (See Figure 1).

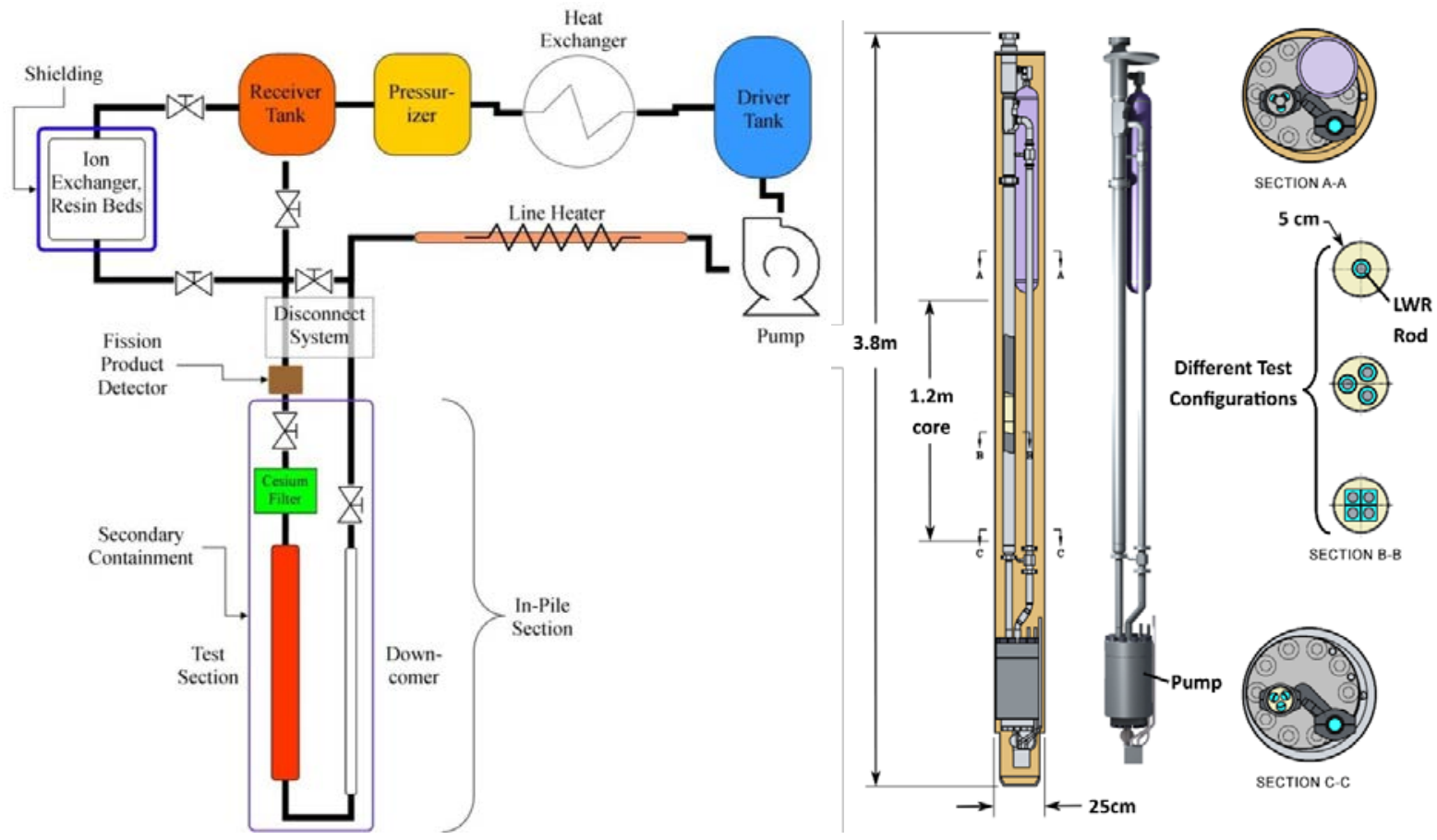

Figure 1. Left: TWERL loop system concept; Right: TWERL self-contained concept.

This decision depends on many design aspects. With respect to thermal-hydraulics, this decision mainly depends on the pump and heat exchanger sizes needed which in turn depend on how many fuel rods (bundle size) are in the test section. The following two analyses are presented here:

- $\quad$ How many fuel rods are needed in the test section?

The number of rods ( 1 single rod, $3 \times 3$ bundle, etc.) should be such as the conditions in at least one rod (the center rod) are most "representative" (with respect to fuel failure mechanisms) to a selected (hot) rod in a full size power plant. The first section of the report analyses how "prototypic" (how close the figures of merit between the experiment and the pressurized water reactor [PWR] are) and how "representative" (how much error reduction can be achieved in the simulations with the gained information from the experiment) the TWERL experiment design (for different number of rods) is compared to a typical PWR. The "representativity" is assessed using a newly developed stochastic methodology. 
- What size are the pump and heat exchangesneeded for a given number of rods in the test section?

Pump and heat exchanger components become bigger with the number of rods, as they should be able to drive the flow through the loop in such a manner to create prototypic PWR flow conditions (velocity, temperature, etc.) in the TWERL test section. The primary concern, therefore, is to sufficiently estimate the flow losses in the loop to be able to appropriately size the pump for a given number of fuel rods in the test section. The second part of the report analyses the pressure drop in the loop for different designs.

\subsection{TWERL Representativity}

One main goal of the TWERL experiment is to be able to create thermal-hydraulic conditions before (and during) the transient tests (planned are Reactivity Initiated Accidents [RIAs] and Loss of Coolant Accidents [LOCAs]) so that the fuel performance (fuel failure mechanisms, cladding behavior, etc.) in the experiment mimics as close as possible the fuel performance in a nuclear power plant.

Traditionally, to assess the "representativity" of the experiment, scaling theory involving expert judgment is applied, i.e., the validation requirements for simulation models rely either on big (expensive) experiments that are very close to the full-size plant or on expert opinion to ensure the smaller (separate effect) facilities provide complete coverage of the physics of interest happening in the full-size plant. One particular challenge is to estimate the uncertainty in the prediction of the simulation model applied to the experiment to be build. At the design stage of the experiment or full-size plant, experimental data are not yet available, and the prediction model has to be validated with a different set of available measured data. This is known as the validation extrapolation problem.

A stochastic approach called "representativity estimation" has been developed that can be applied to experiments for simulation uncertainty reduction and code validation. This methodology, in addition to limit the error of the model prediction for the experiment, also allows to introduce a metric to estimate how representative an experiment is compared to the full-size facility it tries to reproduce, i.e., how much the uncertainty can be reduced for the phenomena of interest happening in the full-size facility.

\subsection{Methodology}

\subsubsection{Mathematical Background}

This section presents the developed methodology for assessing the "representativity" of an experiment compared to the full-size plant. The approach presented here is an adaption of a well-known one used in reactor physics. This section presents the main elements of the original methodology and shows how it is applied to thermal hydraulic experiment design. To assess the validation domain of a simulation model, sensitivity and uncertainty analyses can be employed. If one knows the sensitivity coefficient S of a Figure of Merit (FOM) with respect to an input parameter P, the uncertainty on the integral quantity, i.e., the FOM, can be expressed as

$U^{F O M}=S_{P}^{F O M} \Delta P$

where

$U^{F O M}$ Uncertainty in the target FOM,

$S_{P}^{F O M}$ Linear sensitivity coefficient for the target FOM with respect to an input parameter $P: S=\frac{\partial F O M}{\partial P}$,

$\Delta \mathrm{P} \quad$ Variation (uncertainty) of input parameter $P$. 
Generalizing the uncertainty of Equation (1) to an arbitrary number of parameters $\vec{P}$, one can write for the uncertainty of the FOM:

$U_{\text {Sim }}^{F O M}=\overrightarrow{\nabla F O M_{S l m}} \cdot \overrightarrow{\Delta P_{\text {Sim }}}$

where

$U_{\text {Sim }}^{\text {FOM }} \quad$ Uncertainty in the simulation of the target FOM,

$\overrightarrow{\nabla F O M_{S I m}}$ Gradient of the FOM with respect to the input parameters $\vec{P}$, i.e., the vector of sensitivity coefficients $S_{P_{j}}^{F O M} \forall j$.

$\overrightarrow{\Delta P_{S l m}} \quad$ Variance vector (uncertainties) for input parameters $\vec{P}$.

It can be shown that if experimental data are available, the variance of the input parameters $P$ can be adjusted (the model calibrated) in order to obtain a reduction in uncertainty $\widetilde{U_{S i m}^{F O M}}$ as shown in Equation (3).

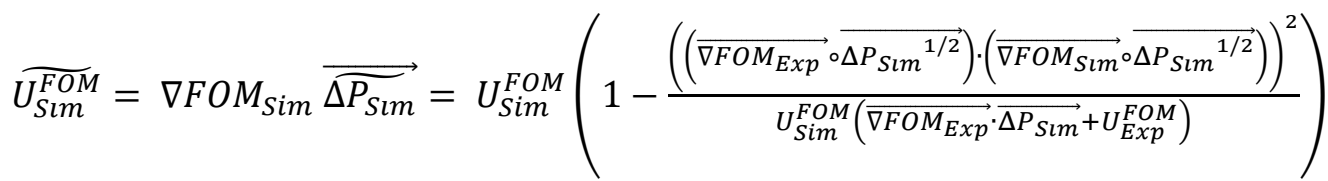

where

$\widetilde{U_{\text {Sim }}^{F O M}} \quad$ Reduced uncertainty in the simulation of the target FOM,

$\widetilde{\widehat{\Delta P_{\text {SIm }}}} \quad$ Adjusted (by experimental results) variance vector for input parameters $\vec{P}$,

$\overrightarrow{\nabla F O M_{E x p}}$ Gradient of the FOM with respect to the input parameters $\vec{P}$ for the experiment, i.e., sensitivity coefficients for the experiment,

$U_{\text {Exp }}^{\text {FOM }} \quad$ Uncertainty in the experiment for the target FOM,

- $\quad$ The Hadamard product of the vectors, i.e., the element-wise multiplication.

From Equation (3), one can see that the most effective reduction in uncertainty is achieved by using experiments with very low uncertainties ( $U_{E x p}^{F O M}$ small) and having variance weighted sensitivity coefficient vectors similar (or identical to) between the experiment and the simulation $\left(\left(\overrightarrow{\nabla F O M_{E x p}} \circ \overrightarrow{\Delta P_{S i m}{ }^{1 / 2}}\right) \|\left(\overrightarrow{\nabla F O M_{S i m}} \circ \overrightarrow{\Delta P_{S i m}{ }^{1 / 2}}\right)\right)$. In fact, it can be shown that the uncertainty reduction of a FOM can be expressed as

$\widetilde{U_{\text {Slm }}^{F O M}}=U_{\text {Sim }}^{F O M}\left(1-R^{F O M}{ }^{2}\right)$

where $R^{\text {FOM }}$ “Representativity” coefficient as defined below.

The "representativity" metric, i.e., the measure of how close the two sensitivity vectors are, is given by the projection of one variance weighted vector onto the other, i.e., 


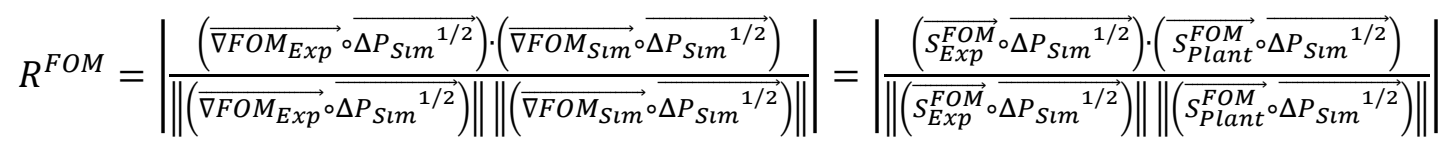

It's worth mentioning that if the two vectors are identical, i.e., the experiment is most representative, the "representativity" index $R^{F O M}$ is 1 which leads to the maximum reduction in uncertainty in Equation (4), while when the two vectors are orthogonal, i.e., the experiment is least representative of the full-size plant, the "representativity" index is 0 which leads to no uncertainty reduction.

The same reasoning to reduce uncertainty can be applied to a simulation of the experiment and a corresponding full-size plant model. In that case, the uncertainty reduction in the full-size plant simulation is maximum when the sensitivity vectors of the experiment (and its simulation) and full-size plant simulations are very close or at the limit identical. A comparison of the sensitivity vectors, i.e., the "representativity" index $R^{F O M}$ between the experiment and a full-size plant simulation can be used as a metric for optimizing the experiment design.

\subsubsection{Implementation in RAVEN}

The above described methodology has been implemented as a workflow in the RAVEN (an uncertainty quantification code) framework. In this way, it is very flexible and can quickly be coupled to any code that simulates the problem and physics of interest. Figure 2 shows the RAVEN workflow using RELAP5-3D, a legacy thermal-hydraulics system code. As one can see, the workflow consists of two layers of RAVEN. This double layer allows to investigate a large parameter space in the outer loop “design parameters" (larger than their uncertainty) for which space the transfer function might be non-linear. The idea is that the inner loop, which perturbs all uncertain parameters within their uncertainties only, will find a more linear response for the small (smaller than in the outer loop) perturbations.

The outer layer RAVEN, called "RAVEN Design," is indicated to be an optimizer in the figure, but can be any sampler available in RAVEN, e.g., a grid (for parametric sweeps) or Monte Carlo sampler. The outer layer can optimize some experiment "design parameters" to find the most representative configuration of the experiment. First, the sampler/optimizer fixes the design parameters for the experiment and sends them to the "Design Preprocessor." The preprocessor is translating the sampled design parameters into a collection of variables that need to be changed in the RELAP5-3D input for the experiment to represent the change in the design parameters. For example, if the design parameter is the flow area, in the RELAP5-3D input not only the flow area, but dependent inputs like the hydraulic diameter and the volume, need to be changed as well. The "Design Preprocessor" is providing all dependent RELAP5-3D inputs and sends them to the inner RAVEN layer, i.e., the "RAVEN Sensitivity" loop.

The "RAVEN Sensitivity" loop is computing the sensitivity coefficients for selected FOMs with respect to all the sensitivity and uncertainty parameters. The sampler for this level is a Monte Carlo sampler which samples all the parameters from their distributions. Similar to the outer layer, the "Sensitivity Preprocessor" translates the sampled parameters into a collection of variables that need to be changed in the RELAP5-3D inputs. The outputs from the outer layer "Design Preprocessor" are fed into the RELAP5-3D Code Interface for the experiment model, while the outputs from the inner loop "Sensitivity Preprocessor" are grouped in three groups (sensitivities for 1) the experiment model only, 2) both, the experiment and the plant model, and 3) the plant model only) and are fed to the corresponding RELAP5-3D Code Interface for the experiment or the plant model. The RELAP5-3D code interfaces generate the input decks for the experiment and the full-size power plant, run both, and collect the FOMs from the RELAP5-3D outputs. Once all Monte Carlo perturbed RELAP5-3D runs are completed, the 
collected FOMs together with the sampled parameters are sent to the "Sensitivity Postprocessor" in the inner loop. This postprocessor computes the normalized sensitivity coefficient vectors as explained earlier.

Finally, the computed normalized sensitivity coefficients are sent back to the outer "RAVEN Design" layer where they are passed into the "Design Postprocessor." This postprocessor assembles the sensitivity coefficients for the experiment models and the plant model into two separate vectors and computes the "representativity" coefficient. This coefficient is then passed back to the sampler of the outer RAVEN layer. In case it is an optimizer, it will compute a new set of design parameters, and the whole loop is repeated until eventually converging to a maximum "representativity" or reaching the maximum number of iterations.

\subsection{Application of "Representativity" to TWERL LOCA Transient}

A "representativity" study of the TWERL experiment for TREAT to a representative PWR has been performed for a large break LOCA transient. First, several FOMs are directly compared between the experiment and the PWR to assess how "prototypic" the conditions are in the experiment. Then, the "representativity" of TWERL to the PWR is assessed with respect to selected FOMs:

- $\quad$ Peak cladding temperature (PCT)

- Maximum fuel centerline to cladding temperature ratio (MaxCtoF)

It is worth mentioning that the selection of the proper FOMs is crucial. The experiment designer has to decide which FOMs are most important. This can be done through feedback from the customers, e.g., the industry or government agencies that look for answers through a particular experiment.

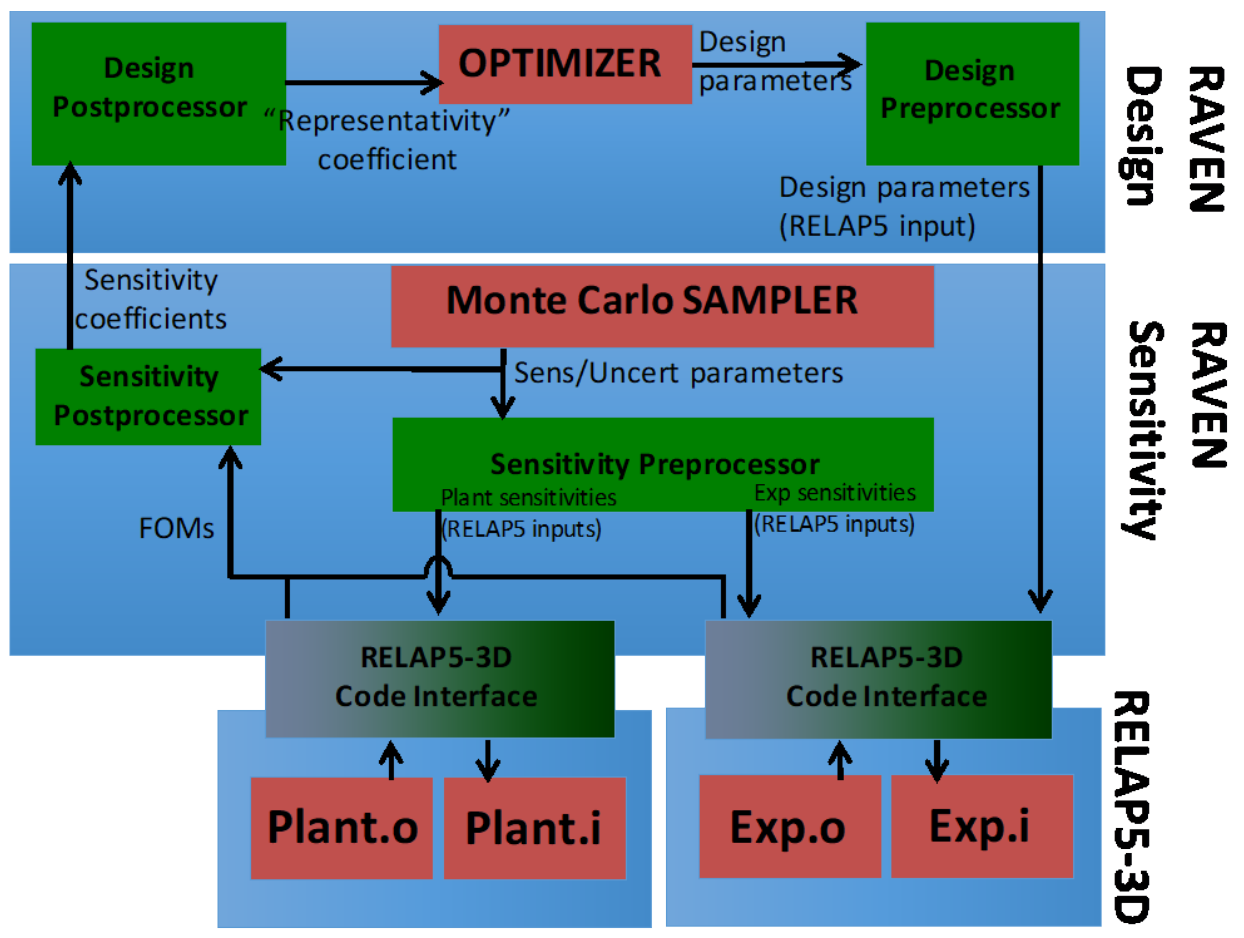

Figure 2. RAVEN workflow for experiment design optimization using experiment "representativity.” 
The Benchmark for Uncertainty Analysis in Modeling (UAM) suggests a list of uncertain input parameters. It also indicates their accuracies and probability density functions. The uncertainty parameters considered in this study are summarized in Table 1. It has been assumed that the uncertainties in the coolant velocity and inlet temperature only apply to the experiment, the uncertainty in the power and heat transfer coefficient applies to both the experiment as well as the plant models, and, finally, the uncertainty in the rod pitch only applies to the plant. The uncertainty in the power is directly applied to the maximum linear power in the case of the PWR model while, for the experiment, the perturbation is applied to the power coupling factor (PCF) between TREAT and the experiment rodlets. These assumptions are not necessarily accurate but serve to illustrate the ability of the developed methodology to address uncertainties that occur only in the experiment or the plant or both.

Table 1. Selected Uncertainty parameters.

\begin{tabular}{|l|c|l|l|}
\hline \multicolumn{1}{|c|}{ Parameter } & Accuracy & \multicolumn{1}{c|}{ PDF } & \multicolumn{1}{c|}{ Applicability } \\
\hline Coolant velocity in channel & $\pm 1 \%$ & Normal & Exp. \\
\hline Coolant inlet temperature & $\pm 0.5 \%$ & Normal & Exp. \\
\hline Power & $\pm 1.5 \%$ & Normal & Exp. and plant \\
\hline Heat transfer coefficient & $\pm 10 \%$ & Normal & Exp. and plant \\
\hline Rod pitch & $\pm 0.5 \%$ & Normal & Plant \\
\hline
\end{tabular}

\subsubsection{Model Description: Representative 3-loop Westinghouse PWR}

To represent the nuclear power plant, a representative 3-loop Westinghouse PWR legacy RELAP5-3D model has been used in this study. The model includes detailed representations of the core and vessel, the primary coolant loops including steam generators and pressurizers, as well as the secondary side feed-water and steam systems. For illustration, the RELAP5-3D reactor vessel and primary coolant loop nodalizations are shown in Figure 3, and the secondary loops are shown in Figure 4. The PWR legacy RELAP5-3D model represents $15 \times 15$ fuel bundles. Since tests in TWERL are expected to represent rodlets based on a $17 \times 17$ fuel bundle design, a single $17 \times 17$ fuel rod was added to the model. A Westinghouse (or Areva) $15 \times 15$ bundle has the same width as the $17 \times 17$ bundle, but the fuel rod outer diameters are slightly different. However, the difference in coolant flow area between the $17 \times 17$ and $15 \times 15$ bundles is less than $0.3 \%$. This means that the coolant velocity through the bundles will be the same, and that the core coolant velocities calculated using legacy RELAP5-3D plant models should be reasonable estimates of the current coolant velocities. 


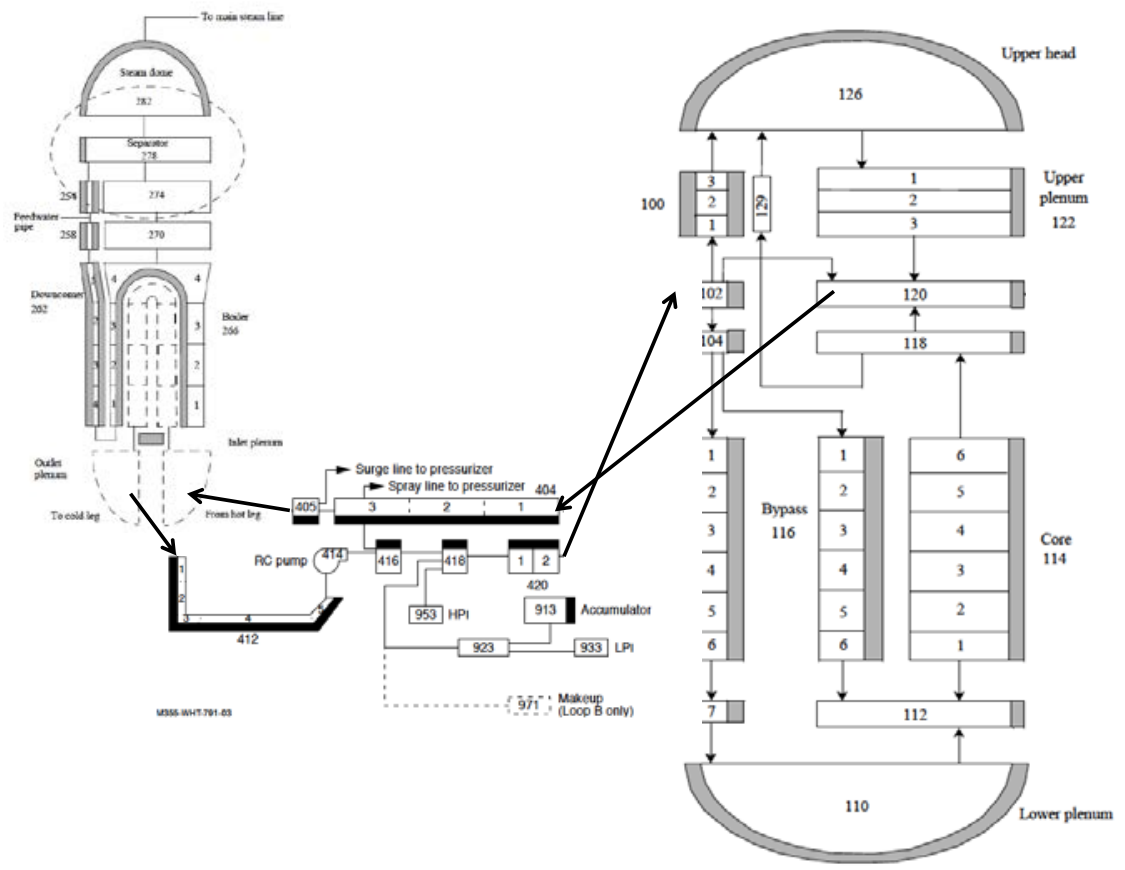

Figure 3. RELAP5-3D model of a typical PWR: vessel and primary coolant loop.

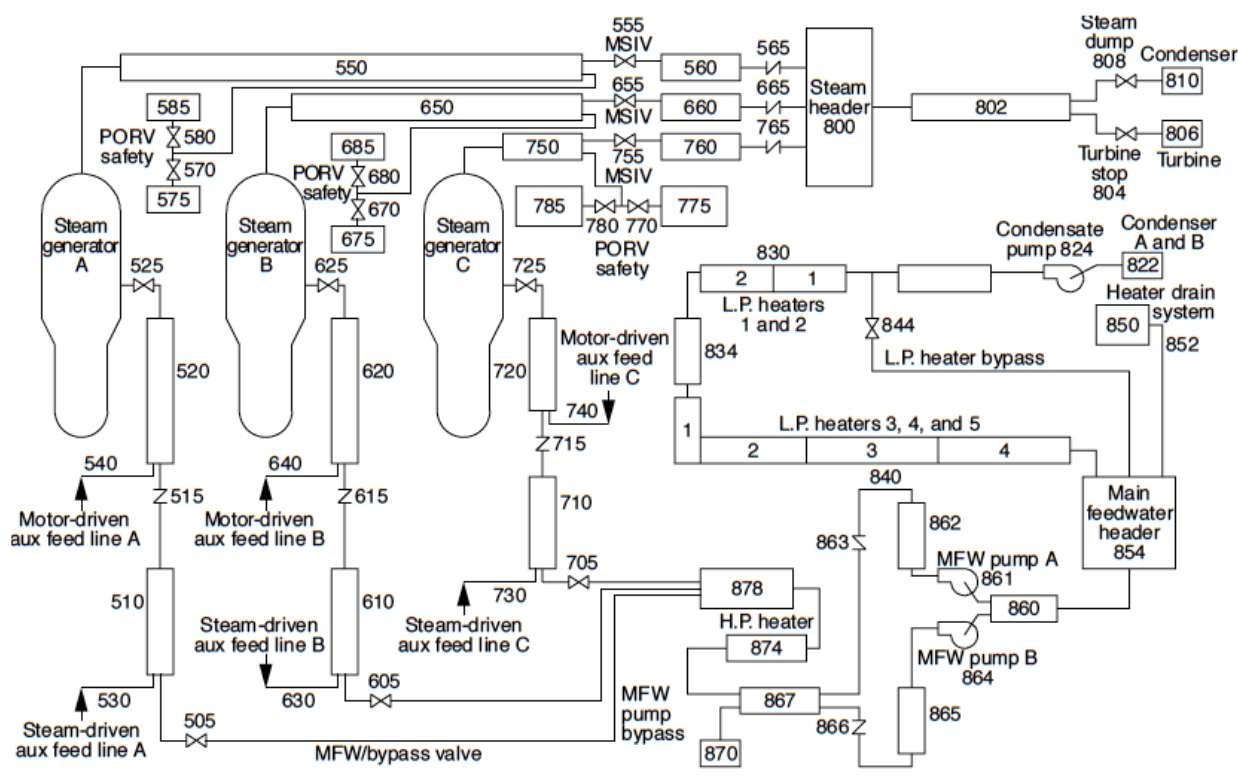

Figure 4. RELAP5-3D model of a typical PWR: secondary coolant loop.

\subsection{Model Description: TWERL Loop}

\subsubsection{Loop}

A thermal-hydraulic RELAP5-3D model of the TWERL loop has been developed. The nodalization is shown in Figure 5. 


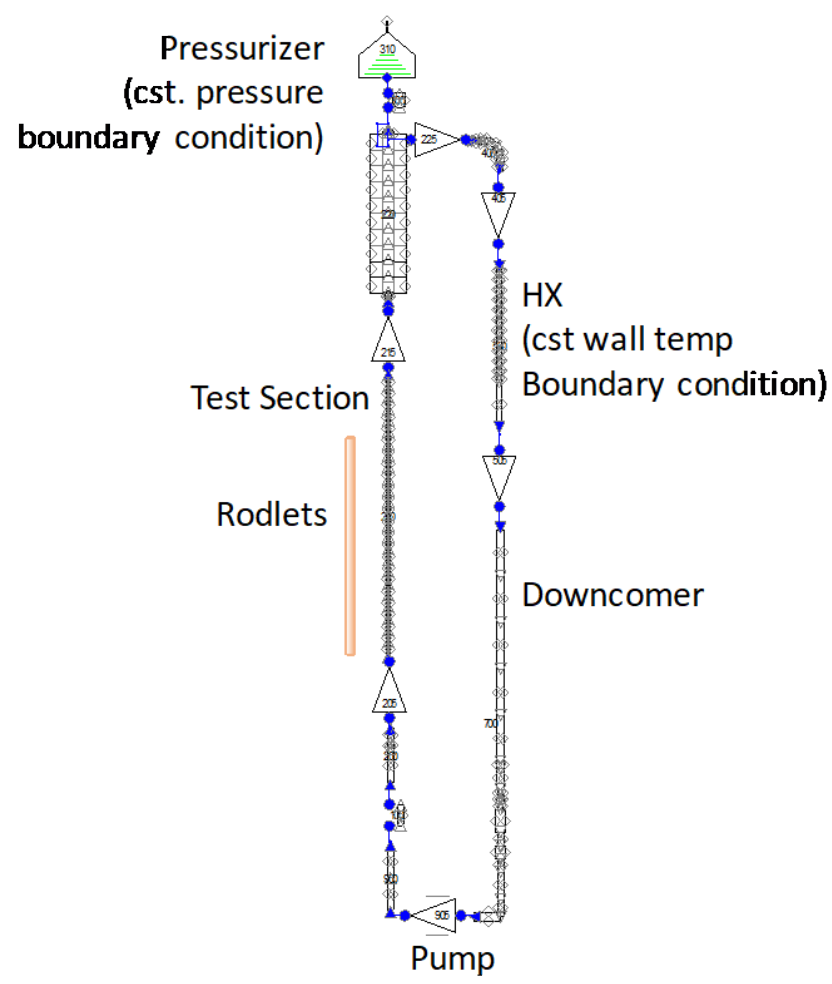

Figure 5. REALP5-3D model of the TWERL loop.

The model contains the following components:

- Pump: The pump is modeled using the "pump" component in RELAP5. The built-in pump curves for a standard Bingham pump are used.

- Below test section tubing: This is $2.34 \mathrm{~cm}$ diameter tubing from the pump to the test section. This tube is $42 \mathrm{~cm}$ long. The abrupt area change into the test section is modeled explicitly (RELAP5 card 1101 is set to 100 to include a code calculated k-loss).

- Test Section: Five different test sections have been modeled and compared. Detailed information of the different test sections can be found in Section 2.5.2.

- Above test section tubing: This is $14 \mathrm{~cm}$ diameter empty tubing from the test section to the pressurizer and return bend; this tubing is $15 \mathrm{~cm}$ long. The abrupt area change from the test section has been modeled explicitly (RELAP5 card 1101 is set to 100 to include a code calculated k-loss).

- Pressurizer: The pressurizer is modeled as “Time Dependent Volume” in RELAP5-3D. During steady state, a constant pressure of 155 bar is imposed. This boundary condition is also used to simulate the expansion tank during the LOCA transient. Different back-up pressures are investigated. The valve opening area to simulate the double guillotine large LOCA is scaled with the "experiment to PWR primary loop inventory” ratio.

- Heat exchanger: To evacuate heat form the rods in the test section and keep thermal-hydraulic conditions (fluid inlet temperature) constant, a heat exchanger will most likely be included in the TWERL design. For simplicity, the model considers a simple counter-current concentric tube heat exchanger. To fix the inlet temperature of the fluid in the RELAP5-3D model, the outer surfaces of 
the heat exchanger tube have been set to a constant temperature, and the heat transfer area multiplier in RELAP5-3D has been set to an arbitrary large number.

- Return tubing: The return tubing is $\sim 2.5 \mathrm{~cm}$ in diameter. This includes the return-bend above the heat exchanger as well as the down-comer connecting the heat exchanger back to the pump. The return bend includes $\mathrm{k}=0.25$ and $\mathrm{k}=1.4$ pressure loss coefficients modeling the abrupt area change from the side connection of the tubing above the test section to the bend. In addition, a $\mathrm{k}=0.1$ pressure loss coefficient is included to model the bend. The inlet and outlet of the heat exchanger abrupt area change has been modeled explicitly (RELAP5 card 1101 is set to 100 to include a code calculated $\mathrm{k}$-loss). The down-comer includes $\mathrm{k}=0.1,2$ times $\mathrm{k}=0.25$ and $\mathrm{k}=1.2$ to model the various bends needed at the bottom of the down-comer to properly connect back to the pump.

- Fuel rod: The model includes a Heat Structure modeling the fuel rods (rodlets) in the test section. This heat structure is coupled to the test section tube, allowing for convective heat transfer between the rods and the coolant. The power in the model is input as power of the TREAT reactor. A power coupling factor (PCF) of 2.5e-6 [W/g per $\mathrm{W}]$ is then used to compute the power generated in the experiment rodlets.

It should be mentioned that no additional pressure losses from instrumentation (flow meter, etc.) have been included in this early TWERL model.

\subsubsection{Test Section}

The "Design Loop" in the RAVEN implementation can change the number of rods in the test section. Like this, the most representative TWERL design as a function of number of rods and characteristic length can be evaluated. Four different test sections with 1, 4, 5, and 9 rods have been considered (see Figure 6). All test sections are $133 \mathrm{~cm}$ long. Table 2 shows the geometrical characteristics (as modeled in RELAP5-3D) of the different test sections.
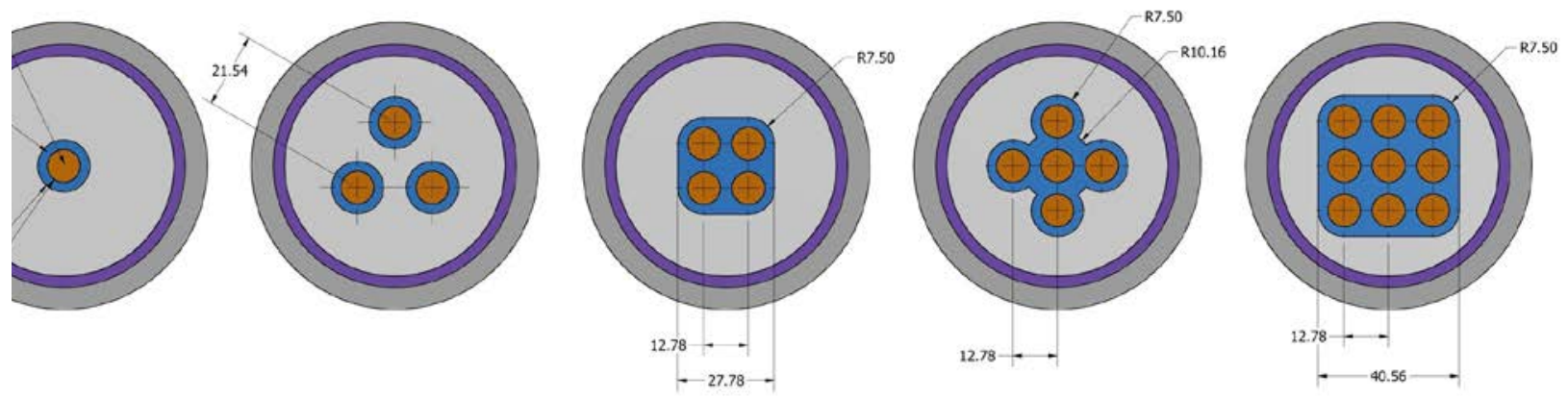

in mm

Figure 6. TWERL test section concepts with 1, 4, 5, and 9 rods.

Table 2. Test section characteristics for different TWERL designs

\begin{tabular}{|l|c|c|c|c|}
\hline \multicolumn{1}{|c|}{ \# of rods } & $\mathbf{1}$ & $\mathbf{4}$ & $\mathbf{5}$ & $\mathbf{9}$ \\
\hline Flow area $\left[\mathbf{c m}^{2}\right]$ & 1.058 & 4.399 & 5.159 & 9.589 \\
\hline Flow area/rod $\left[\mathbf{c m}^{2}\right]$ & 1.058 & 1.100 & 1.032 & 1.065 \\
\hline $\mathbf{D}_{\mathbf{h}}[\mathbf{c m}]$ & 0.550 & 0.809 & 0.698 & 0.918 \\
\hline
\end{tabular}




\subsubsection{LOCA Simulations}

The goal is to compute the TWERL experiment "representativity" with respect to a large break LOCA transient. The corresponding simulation sequences for the PWR and the experiment are as follows:

- PWR: First, the RELAP5-3D steady state input is run to get a converged steady state for the nominal operating conditions in the PWR. Once steady state conditions are established, the LOCA break valve is opened, and the time is reset to zero, i.e., the LOCA transient starts at time zero from PWR steady state conditions. During the transient, it is assumed that the plant protection system is working, i.e., the reactor is shut down by the SCRAM signal and the emergency core cooling system (ECCS) is injecting water into the core. Power follows a PWR decay heat curve.

- TWERL: For the TWERL experiment, first the coolant and all structures (fuel, walls, heat exchanger, etc.) are initialized at the heat exchanger outlet temperature, i.e., at cold stand-by. The transient is then started from this condition. The TREAT core power is quickly risen to a certain value (different values are studied) and held constant. This will heat up the fuel in the experiment and establish temperature distributions in the coolant and rodlets (the coolant pump is running). Once the PCT in the experiment reaches the reference PCT for normal operation in a PWR (626.5 K), the LOCA break valve is opened which connects the loop to the expansions tank (different back-up pressure boundary conditions are studied). The time is re-set to zero when the LOCA starts, e.g., the fuel heat-up phase is happening before time zero (negative time) in the plots later in the LOCA Results, Section 2.5.4. This time reset aligns the time between the PWR and TWERL simulation and makes time dependent comparisons of FOMs easier. At the same time as the LOCA starts, the TREAT power starts following a power shape that mimics PWR decay heat in the experiment rodlets. In addition, as soon as the LOCA starts, the coolant pump is tripped and cast down linearly.

\subsubsection{LOCA Results}

This section presents the simulation results for the comparison of different TWERL loop LOCA transients to a LOCA simulation for a typical 3 loop Westinghouse PWR. The "RAVEN sensitivity" loop (see Figure 2) perturbed the uncertain parameters (for the experiment and representative plant models) indicated in Table 1. The "RAVEN design loop" (see Figure 2), on the other hand, is looping over the following different (loop and transient) design parameters (for the experiment only):

- Number of rodlets per test section: The four test section designs as explained above in Section 2.5.2 are investigated, i.e., 1, 4, 5 and 9-rod test sections have been compared.

- Back-up pressure: This is the final pressure after the TWRL loop has been depressurized, i.e., the equilibrium pressure reached after connecting the loop inventory to the expansion tank. Two different pressures ( 1 bar and 10 bar) have been investigated.

- TREAT heat-up power: Two different TREAT powers (100MW and 500MW) to heat up the experiment rodlets to PWR conditions have been compared (for details see Section 2.5.3).

- Coolant velocity: One of the TWERL design goals is to create prototypical PWR conditions (in terms of fluid velocity and temperature) inside the test section. Three PWR plant models were run to check steady state core conditions; the results are shown in Table 3.

Table 3. Representative commercial plant steady state conditions.

\begin{tabular}{|l|c|c|c|c|}
\hline \multicolumn{1}{|c|}{ Plant } & $\begin{array}{c}\text { Core inlet T } \\
{[\mathbf{K}]}\end{array}$ & $\begin{array}{c}\text { Core outlet T } \\
{[\mathbf{K}]}\end{array}$ & $\begin{array}{c}\text { Lower core } \\
\text { velocity [m/s] }\end{array}$ & $\begin{array}{c}\text { Upper core } \\
\text { velocity [m/s] }\end{array}$ \\
\hline Westinghouse 4-loop & 559 & 593 & 5.50 & 5.27 \\
\hline Westinghouse 3-loop & 560 & 593 & 4.57 & 4.91 \\
\hline Westinghouse 4-loop & 567 & 600 & 4.66 & 5.06 \\
\hline
\end{tabular}


Two different pump speeds have been investigated to achieve two different coolant velocities in the test section ( 4.5 and $5.5 \mathrm{~m} / \mathrm{s}$ ). It is worth mentioning that these coolant velocities only exist during the experiment fuel heat-up phase, and the coolant pump is tripped as soon as the LOCA transient starts.

All figures shown in this section show the uncertainty band generated on the FOMs by the uncertain parameters in Table 1. The minimum and maximum are shown with thick lines, while all realizations are shown with thinner lines (150 uncertainty realizations have been run for each design and transient parameter combination).

Figure 7 shows the pressure evolution for the TWERL LOCA compared to the PWR LOCA. One can see that the pressure evolution is well captured, i.e., is prototypic with respect to the PWR. The figures show the evolution for the 1-rod design only (indicating the back-up pressure, TREAT power, and coolant velocity sensitivities). The other rod designs show a very similar behavior for the pressure evolution and, therefore, are not shown here.
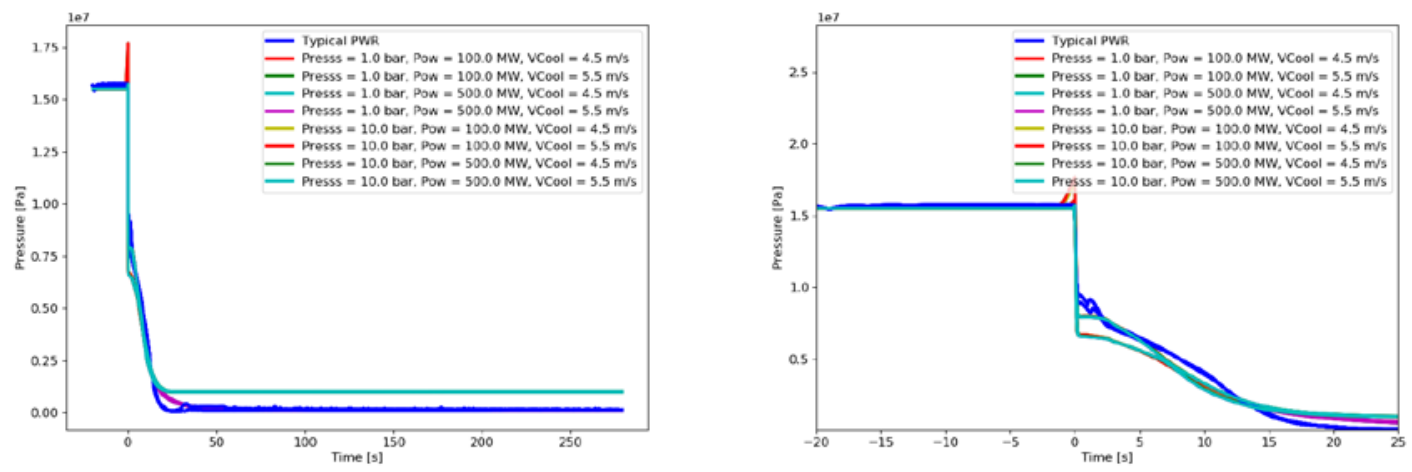

Figure 7. Pressure evolution for TWERL LOCA compared to PWR large break LOCA (1-rod test section design). Left: 300 second transient. Right: Zoom of first 25 seconds of transient.

Next, a comparison for the first figure of merit, the peak cladding temperature (PCT), is shown. Figure 8 to Figure 15 show the PCT evolution (300 seconds and zoom into first 25 seconds) for the different transient design parameters (back-up pressure, TREAT power, and coolant velocity sensitivities) for the 1 rodlet test section design. The following observations can be made:

- The coolant velocity has no impact on the evolution of the transient. It is worth recalling that the coolant pump only runs during the heat-up portion of the transient and is tripped and cast down once the LOCA transient starts. After the pump cast down, natural convection establishes in the loop. The fact that the coolant velocity during the heat-up has no impact on the transient that follows indicates that the initial fuel temperature (at the start of the LOCA) is only slightly impacted by the coolant velocity (for the investigated range of $4.5-5.5 \mathrm{~m} / \mathrm{s}$ ). In addition, it is worth mentioning that the modeled heat exchanger is somewhat overdesigned, i.e., independent of the coolant velocity, the heat exchanger outlet temperature is the same. This might not be true for a more detailed heat exchanger design, and the impact of the coolant velocity might become more important.

- The TREAT power level to heat up the fuel in the experiment has a limited impact on the evolution of the LOCA transient. This indicates that the time for heating up the fuel rodlet does not impact the temperature distribution at the beginning of the LOCA. It looks like the heat-up times for $100 \mathrm{MW}$ $(0.98 \mathrm{sec})$ and $500 \mathrm{MW}(0.18 \mathrm{sec})$ are both slow enough compared to the time needed to establish a developed temperature distribution. 

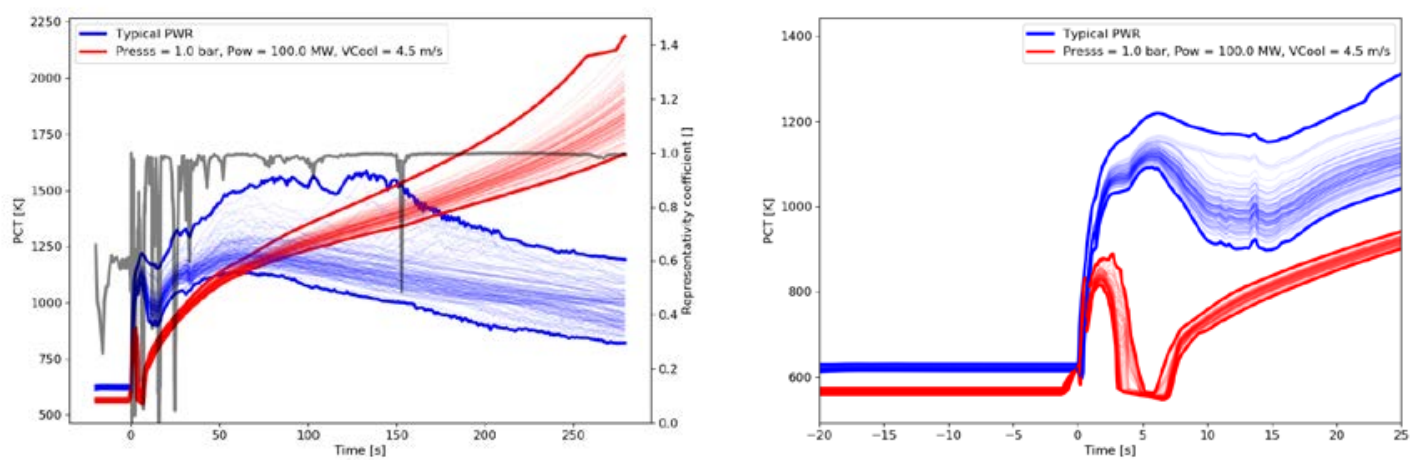

Figure 8. PCT for 1-rod design, 1 bar back-up pressure, 100MW TREAT heating power and $4.5 \mathrm{~m} / \mathrm{s}$ coolant velocity. Left: 300 second transient with representativity on right side axis. Right: Zoom of first 25 seconds of transient.
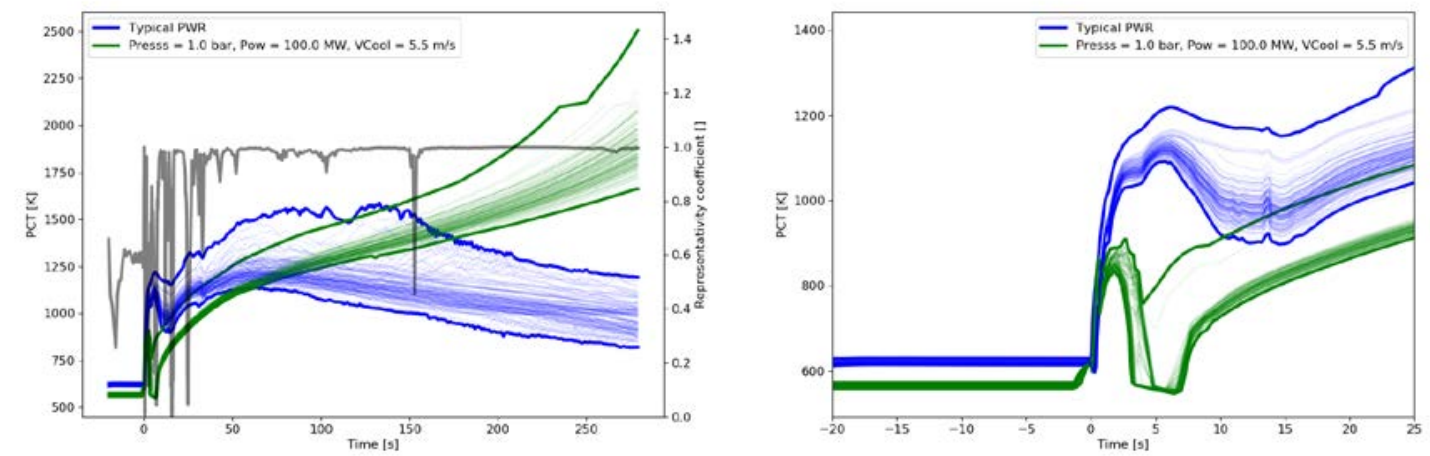

Figure 9. PCT for 1-rod design, 1 bar back-up pressure, 100MW TREAT heating power and $5.5 \mathrm{~m} / \mathrm{s}$ coolant velocity. Left: 300 second transient with representativity on right side axis. Right: Zoom of first 25 seconds of transient.
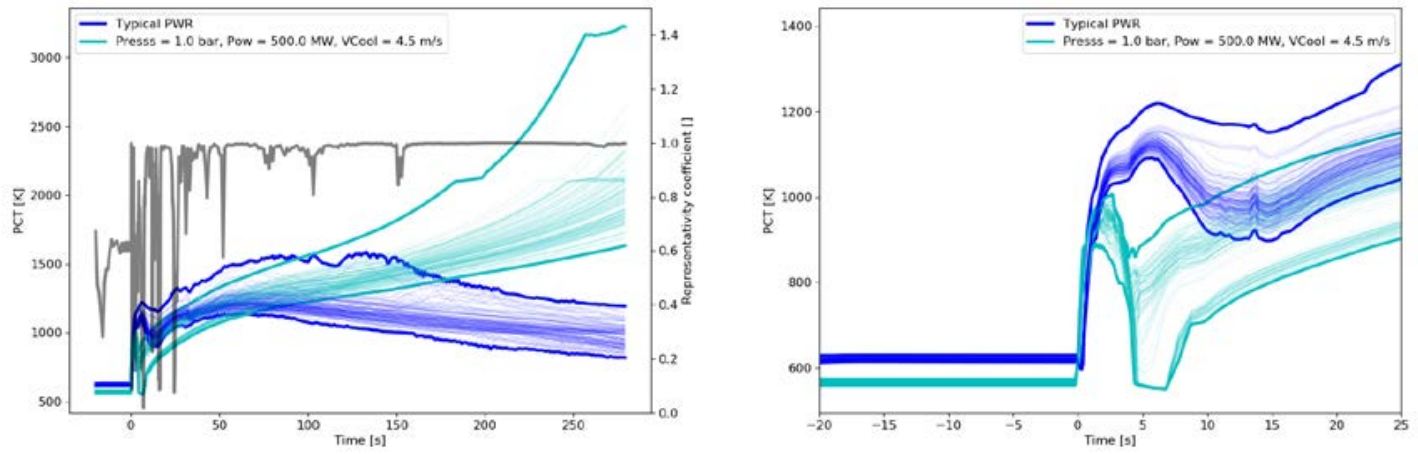

Figure 10. PCT for 1-rod design, 1 bar back-up pressure, 500MW TREAT heating power and $4.5 \mathrm{~m} / \mathrm{s}$ coolant velocity. Left: 300 second transient with representativity on right side axis. Right: Zoom of first 25 seconds of transient. 

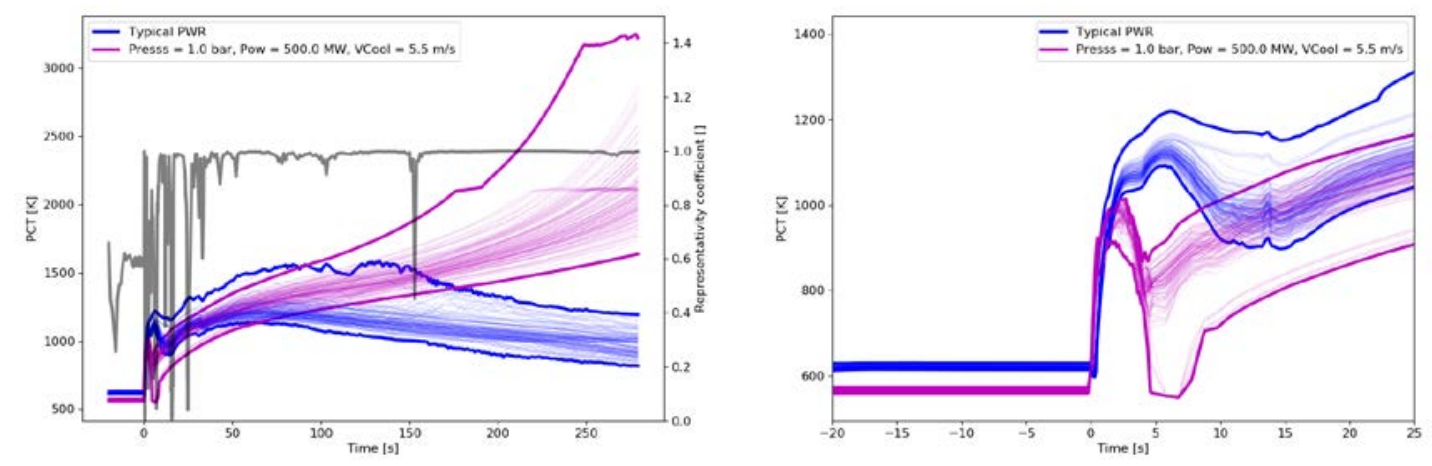

Figure 11. PCT for 1-rod design, 1 bar back-up pressure, 500MW TREAT heating power and $5.5 \mathrm{~m} / \mathrm{s}$ coolant velocity. Left: 300 second transient with representativity on right side axis. Right: Zoom of first 25 seconds of transient.
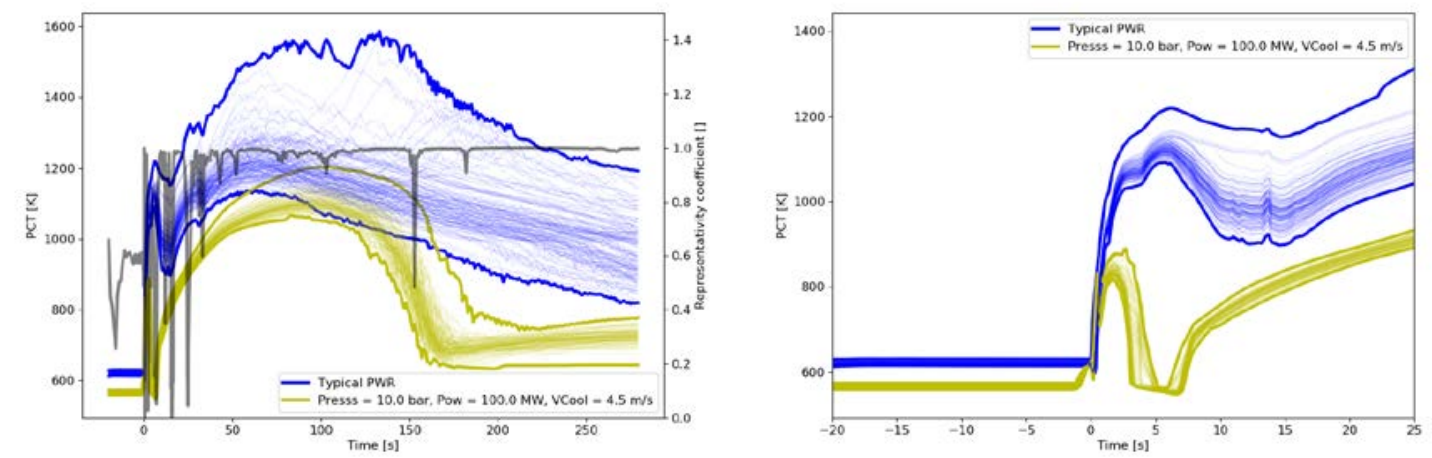

Figure 12. PCT for 1-rod design, 10 bar back-up pressure, 100MW TREAT heating power and $4.5 \mathrm{~m} / \mathrm{s}$ coolant velocity. Left: 300 second transient with representativity on right side axis. Right: Zoom of first 25 seconds of transient.
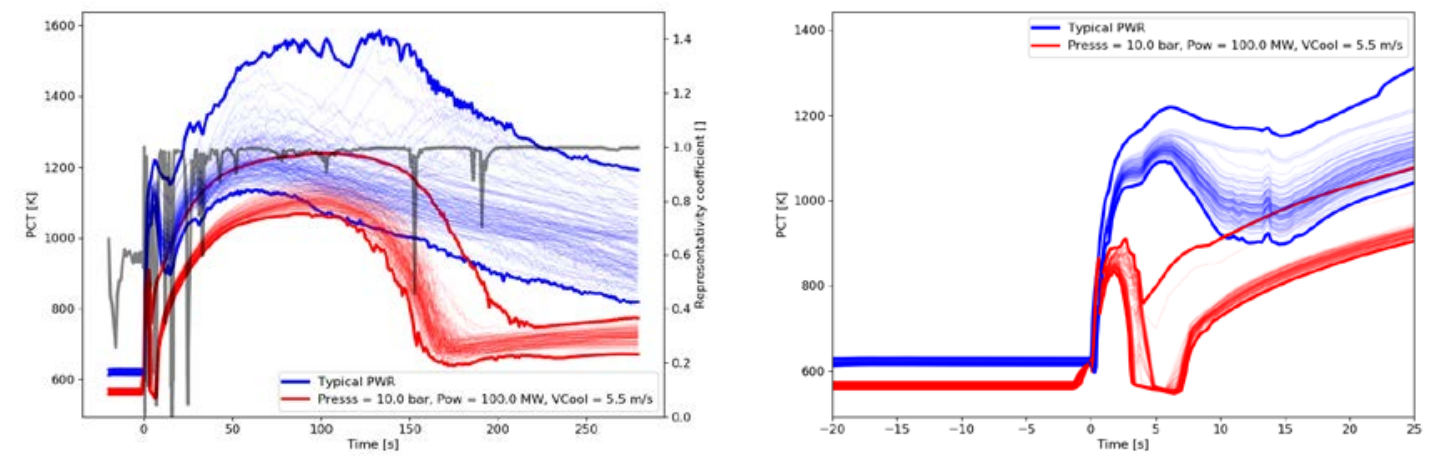

Figure 13. PCT for 1-rod design, 10 bar back-up pressure, 100MW TREAT heating power and $5.5 \mathrm{~m} / \mathrm{s}$ coolant velocity. Left: 300 second transient with representativity on right side axis. Right: Zoom of first 25 seconds of transient. 

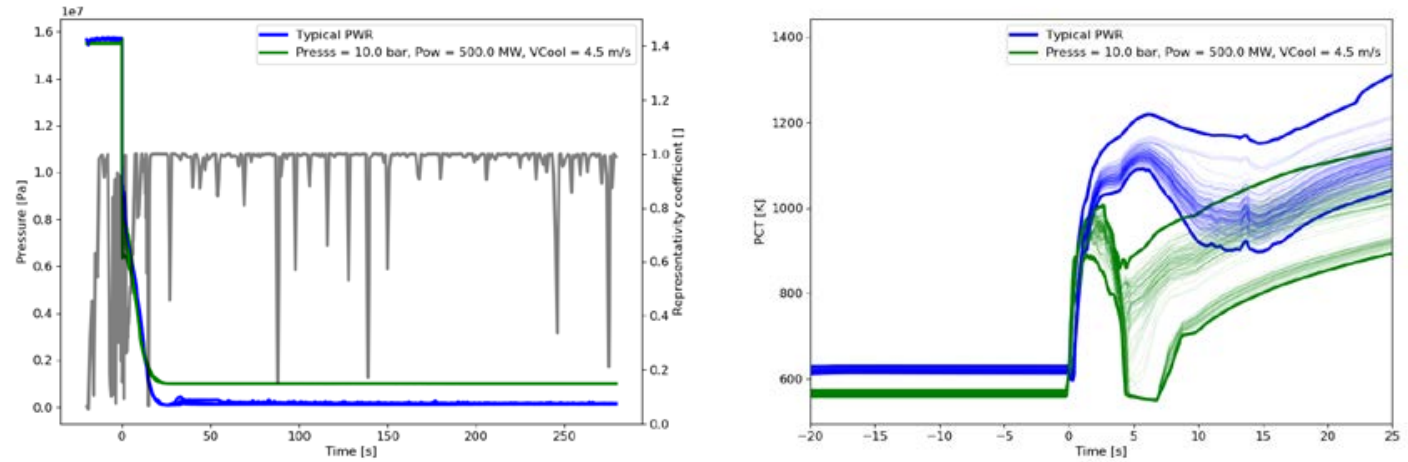

Figure 14. PCT for 1-rod design, 10 bar back-up pressure, 500MW TREAT heating power and $4.5 \mathrm{~m} / \mathrm{s}$ coolant velocity. Left: 300 second transient with representativity on right side axis. Right: Zoom of first 25 seconds of transient.
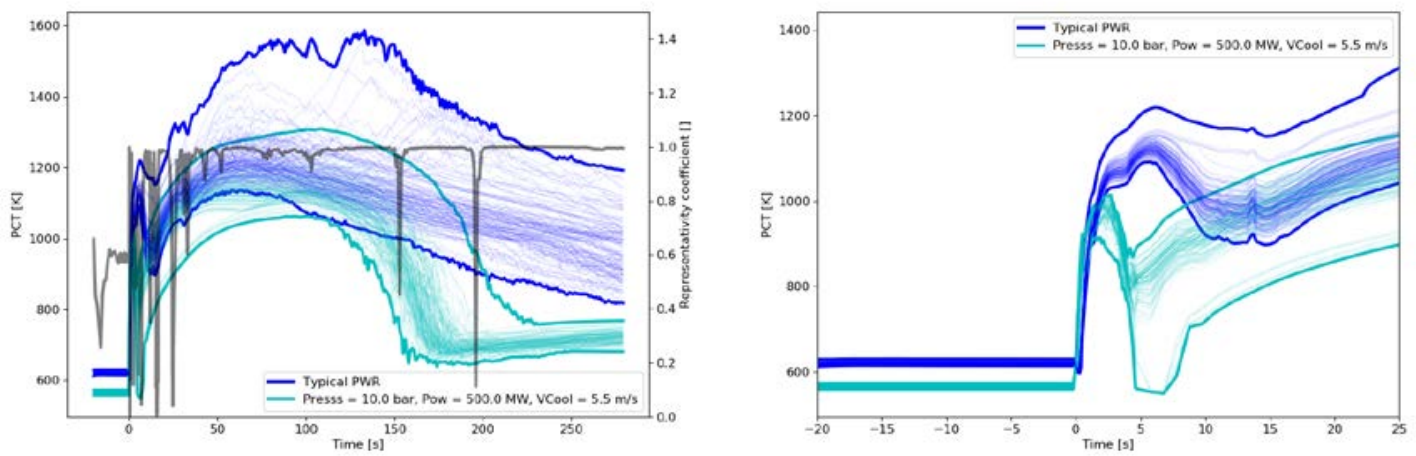

Figure 15. PCT for 1-rod design, 10 bar back-up pressure, 500MW TREAT heating power and $5.5 \mathrm{~m} / \mathrm{s}$ coolant velocity. Left: 300 second transient with representativity on right side axis. Right: Zoom of first 25 seconds of transient.

It has been confirmed (not shown) that the coolant velocity and the TREAT power level also have limited impact on the transients for the other test section designs (4, 5 and 9 rods). Figure 16 to Figure 21 show the PCT evolution (300 sec and 25 second zoom) for the other test section designs. Only the sensitivity to the back-up pressure is shown. Comparing all designs, one can see that:

- Prototypicality: In general, the 1 bar back-up pressure cases overheat the fuel compared to the PWR, while the 10 bar back-up pressure cases underheat the fuel in the long run of the transient (minutes). It seems there exists an intermediate back-up pressure that leads to most similar (prototypic) maximum PCT compared to the reference PWR. The general short time behavior (blowdown, seconds) of the PCT is independent of the back-up pressure. The different test section designs (number of rodlets) lead to similar PCT behavior using this simple model.

- Representativity: Like the PCT behavior is similar for the different designs, so is the representativity. The representativity is quite good, i.e., close to 1.0 for all test section designs. 

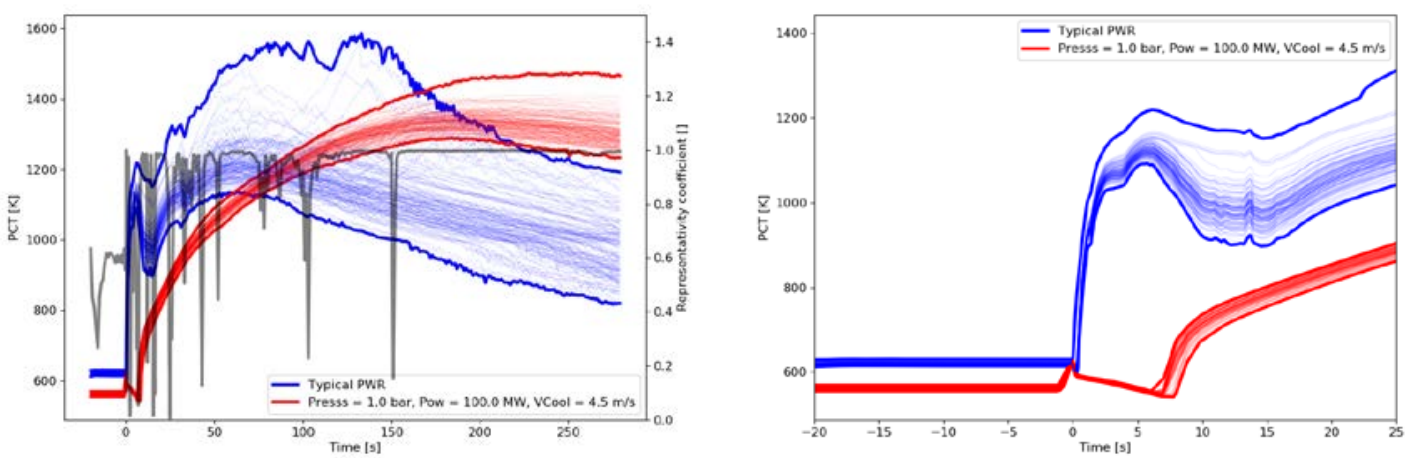

Figure 16. PCT for 4-rod design, 1 bar back-up pressure, 100MW TREAT heating power and $4.5 \mathrm{~m} / \mathrm{s}$ coolant velocity. Left: 300 second transient with representativity on right side axis. Right: Zoom of first 25 seconds of transient.
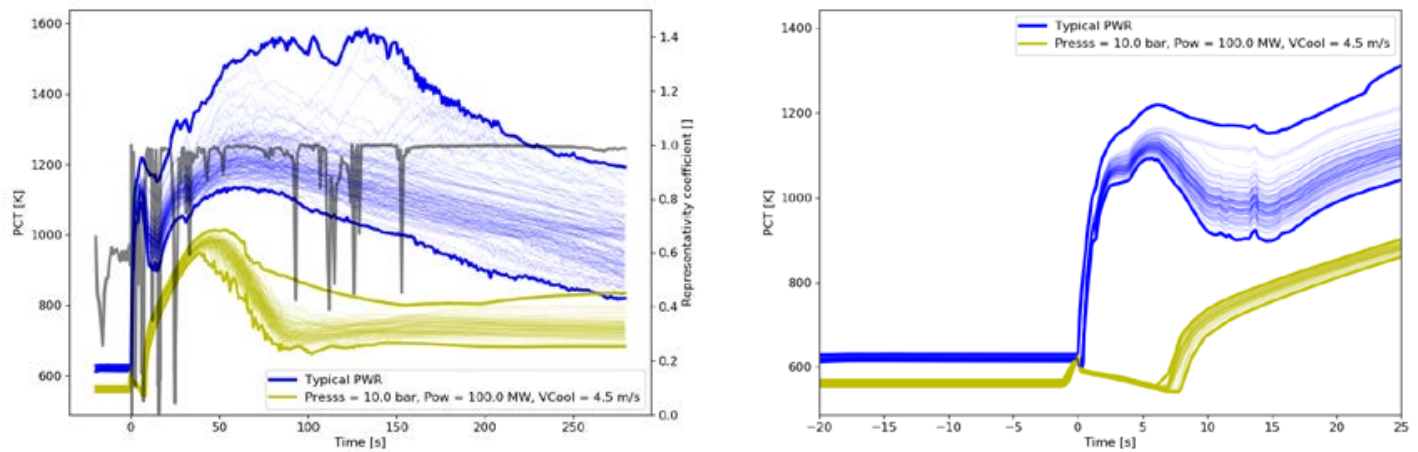

Figure 17. PCT for 4-rod design, 10 bar back-up pressure, 100MW TREAT heating power and $4.5 \mathrm{~m} / \mathrm{s}$ coolant velocity. Left: 300 second transient with representativity on right side axis. Right: Zoom of first 25 seconds of transient.
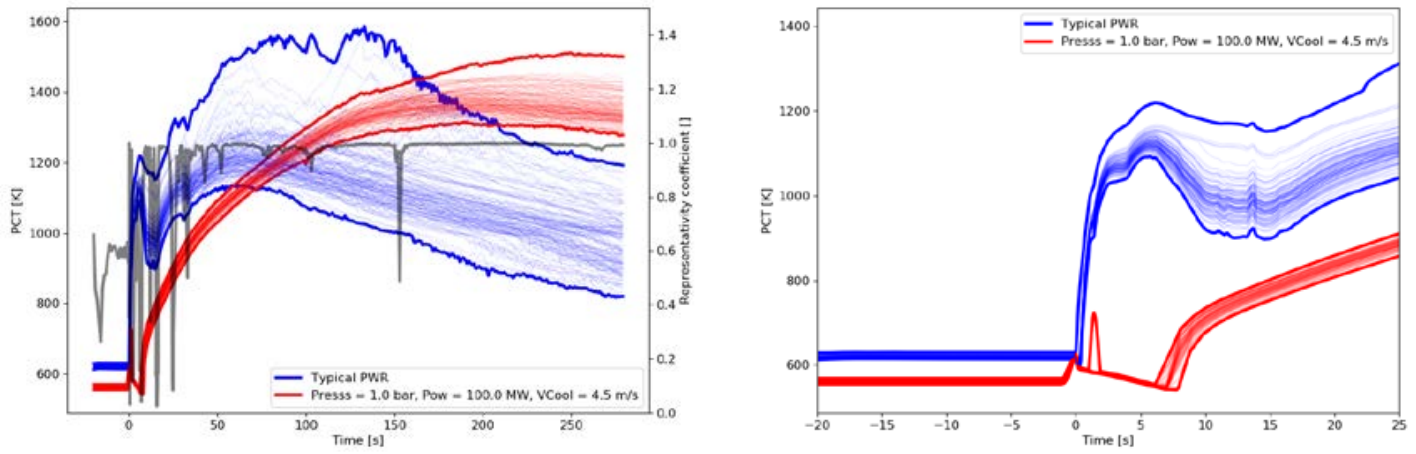

Figure 18. PCT for 5-rod design, 1 bar back-up pressure, 100MW TREAT heating power and $4.5 \mathrm{~m} / \mathrm{s}$ coolant velocity. Left: 300 second transient with representativity on right side axis. Right: Zoom of first 25 seconds of transient. 

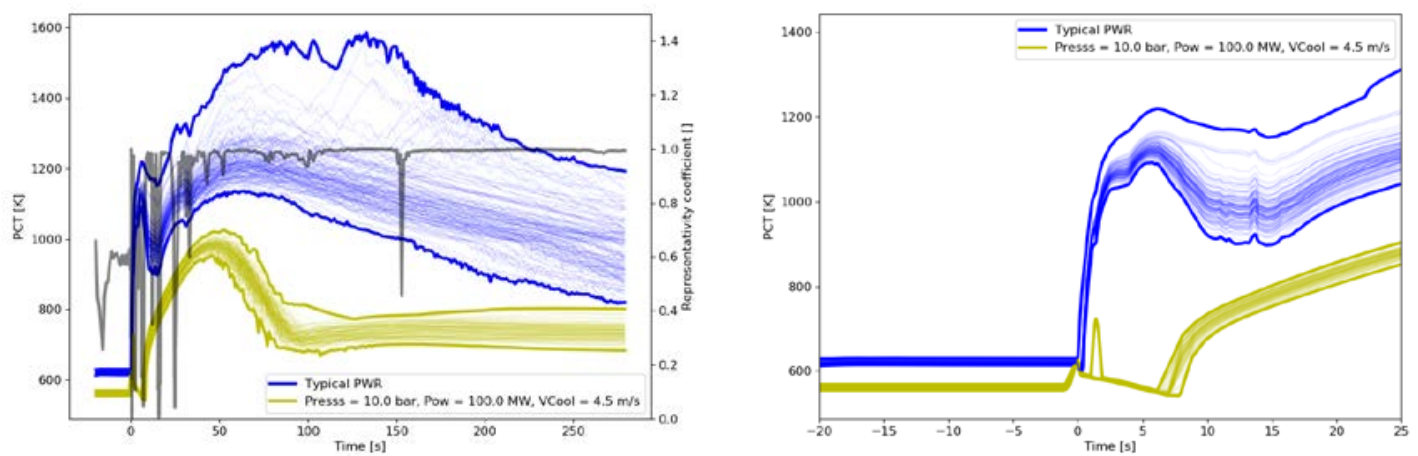

Figure 19. PCT for 5-rod design, 10 bar back-up pressure, 100MW TREAT heating power and $4.5 \mathrm{~m} / \mathrm{s}$ coolant velocity. Left: 300 second transient with representativity on right side axis. Right: Zoom of first 25 seconds of transient.
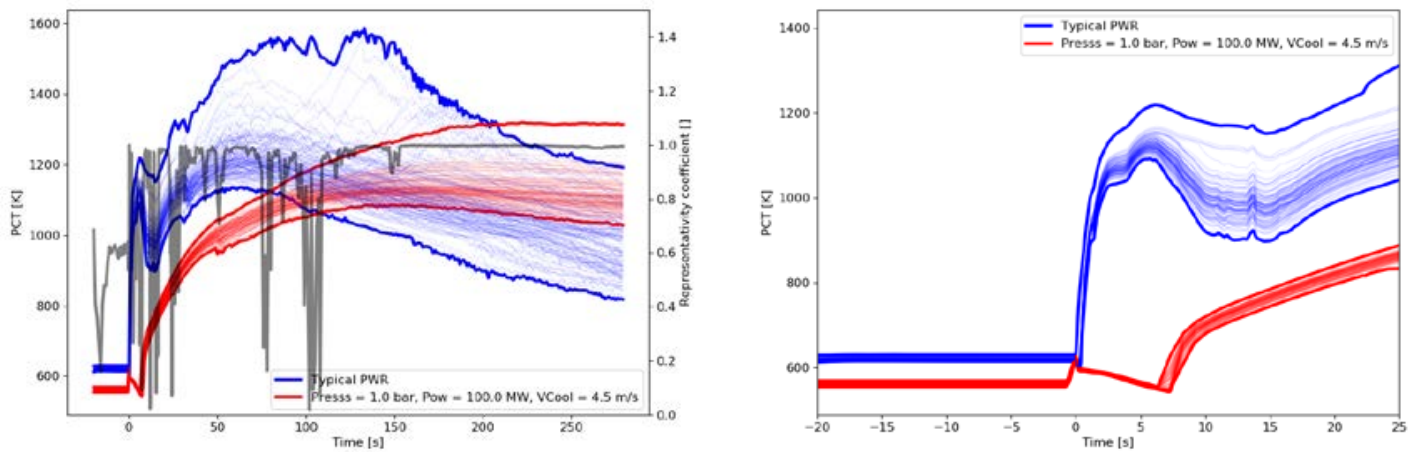

Figure 20. PCT for 9-rod design, 1 bar back-up pressure, 100MW TREAT heating power and $4.5 \mathrm{~m} / \mathrm{s}$ coolant velocity. Left: 300 second transient with representativity on right side axis. Right: Zoom of first 25 seconds of transient.
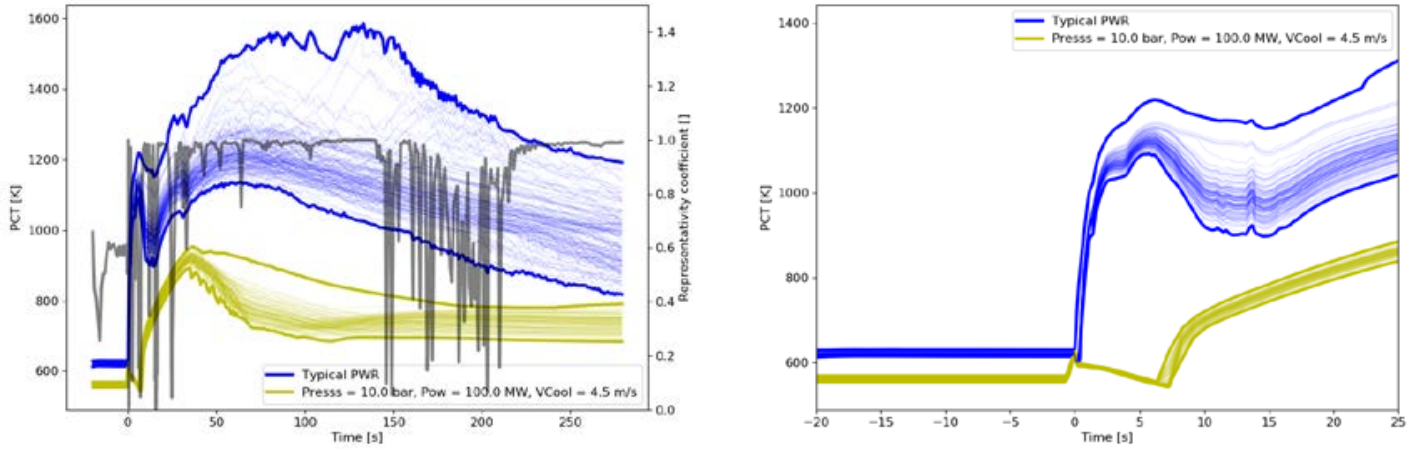

Figure 21. PCT for 9-rod design, 10 bar back-up pressure, 100MW TREAT heating power and $4.5 \mathrm{~m} / \mathrm{s}$ coolant velocity. Left: 300 second transient with representativity on right side axis. Right: Zoom of first 25 seconds of transient. 
Figure 22 to Figure 29 show the second figure of merit, i.e. is the maximum cladding to center line fuel temperature ratio (MaxCtoF). Recalling that the experiment is initialized at a uniform temperature, MaxCtoF $=1$ before the TREAT fuel heat-up transient starts ( -1.0 sec in the figures). At that point, the fuel is heated up, and a fuel temperature distribution is established until time $=0$ in the figures, where the LOCA transient starts (triggered by PCT). It can be seen that for the 9-rod test section (Figure 28 and Figure 29, right plot), MaxCtoF does not reach the PWR steady state value (MaxCtoF 0.4), which indicates that, in this case, the cladding heats up faster than the fuel center compared to other cases. This makes the 9-rod test section the least prototypic. The LOCA parameters investigated (back-up pressure, TREAT power, and coolant velocity) all have a limited impact on MaxCtoF (since there is only decay power, MaxCtoF 1.0 for all cases [experiment and PWR] in the long run). As for PCT, the short term behavior (seconds) of MaxCtoF is rather independent of the LOCA parameters studied. None of the test designs capture the PWR MaxCtoF slope and only catch up about 4-5 seconds later. On the other hand, the representativity is less 'stable' in time compared to the one for PCT but also is generally very good.
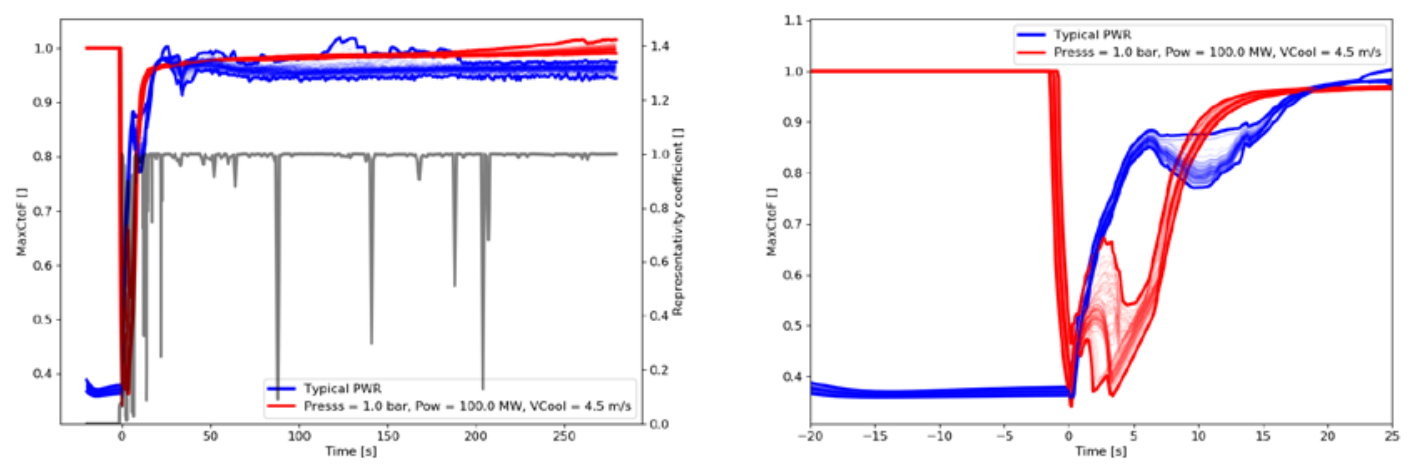

Figure 22. Maximum cladding to center line fuel temperature for 1-rod design, 1 bar back-up pressure, 100MW TREAT heating power and $4.5 \mathrm{~m} / \mathrm{s}$ coolant velocity. Left: 300 second transient with representativity on right side axis. Right: Zoom of first 25 seconds of transient.
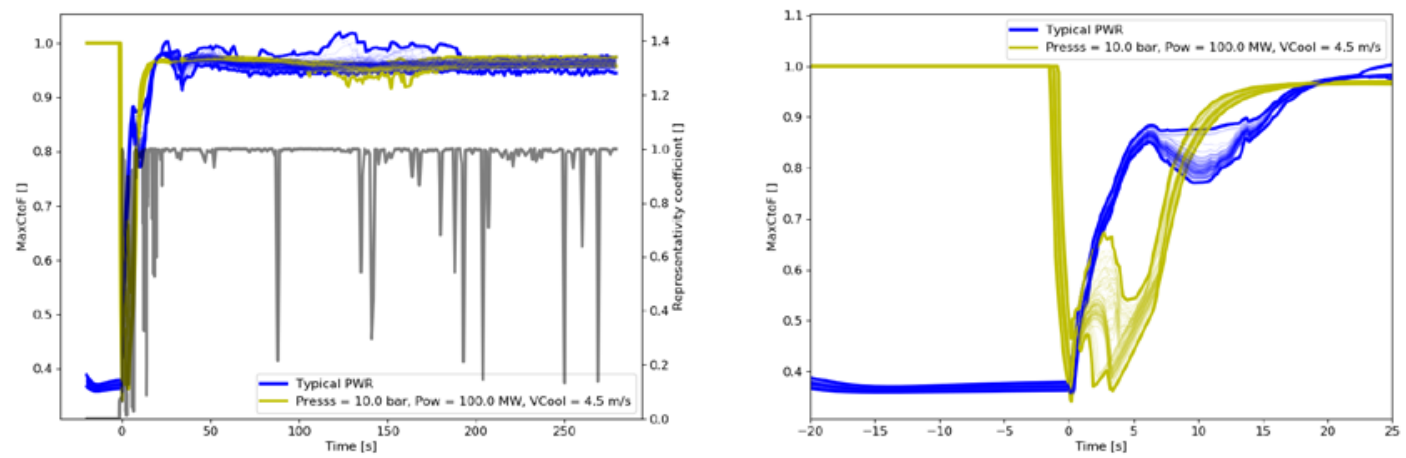

Figure 23. Maximum cladding to center line fuel temperature for 1-rod design, 10 bar back-up pressure, 100MW TREAT heating power and $4.5 \mathrm{~m} / \mathrm{s}$ coolant velocity. Left: 300 second transient with representativity on right side axis. Right: Zoom of first 25 seconds of transient. 

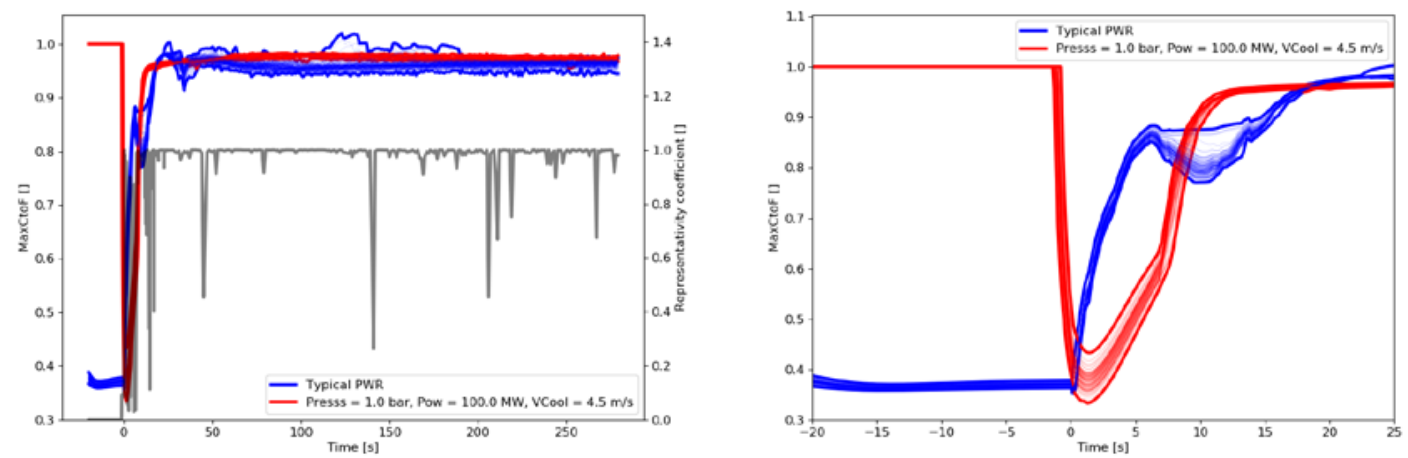

Figure 24. Maximum cladding to center line fuel temperature for 4-rod design, 1 bar back-up pressure, 100MW TREAT heating power and $4.5 \mathrm{~m} / \mathrm{s}$ coolant velocity. Left: 300 second transient with representativity on right side axis. Right: Zoom of first 25 seconds of transient.
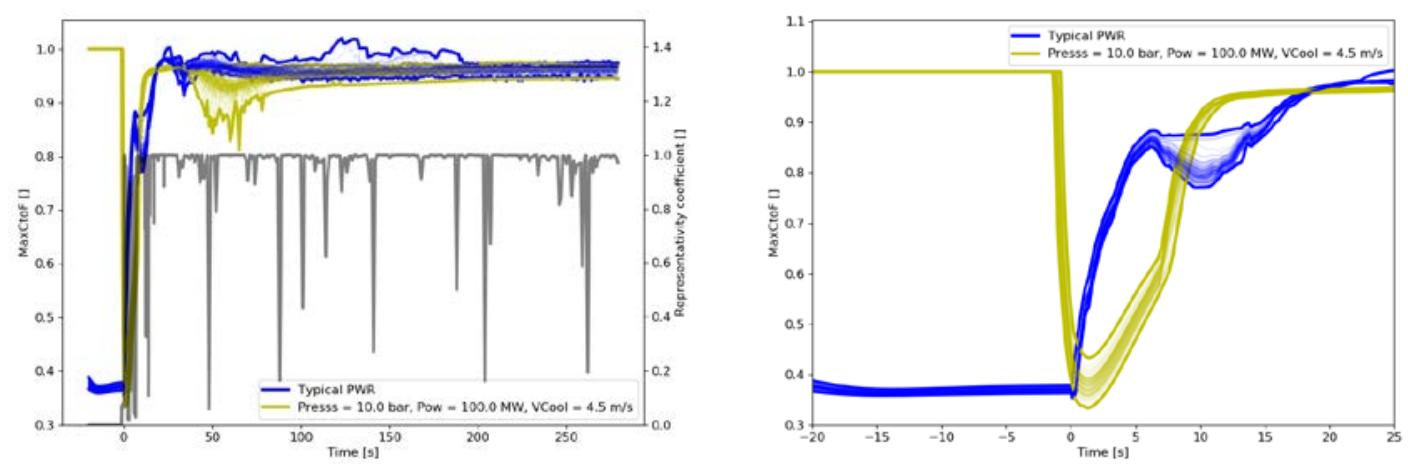

Figure 25. Maximum cladding to center line fuel temperature for 4-rod design, 10 bar back-up pressure, 100MW TREAT heating power and $4.5 \mathrm{~m} / \mathrm{s}$ coolant velocity. Left: 300 second transient with representativity on right side axis. Right: Zoom of first 25 seconds of transient.
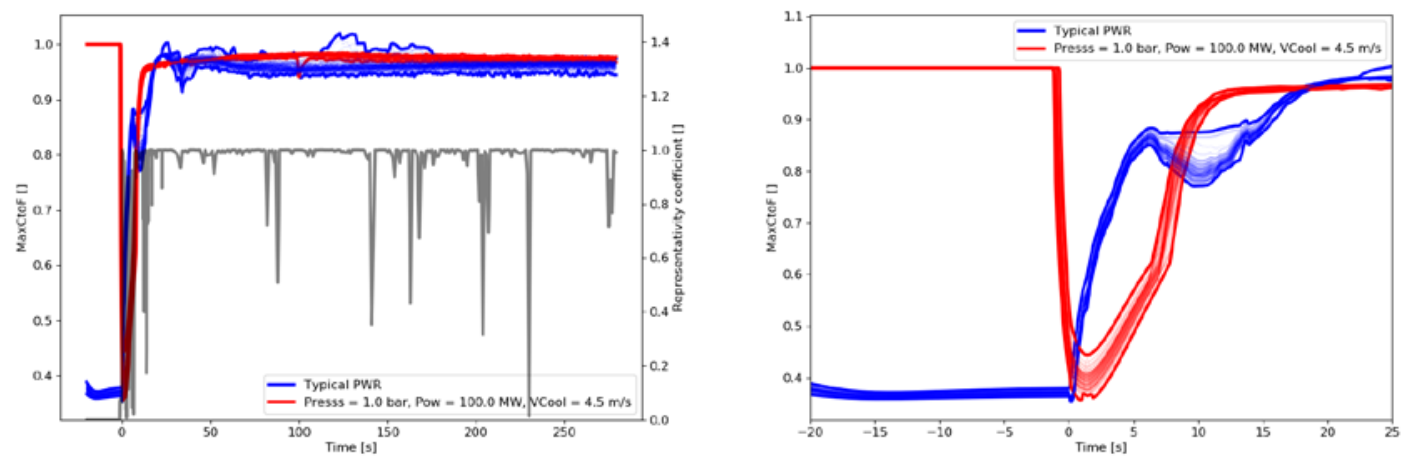

Figure 26. Maximum cladding to center line fuel temperature for 5-rod design, 1 bar back-up pressure, 100MW TREAT heating power and $4.5 \mathrm{~m} / \mathrm{s}$ coolant velocity. Left: 300 second transient with representativity on right side axis. Right: Zoom of first 25 seconds of transient. 

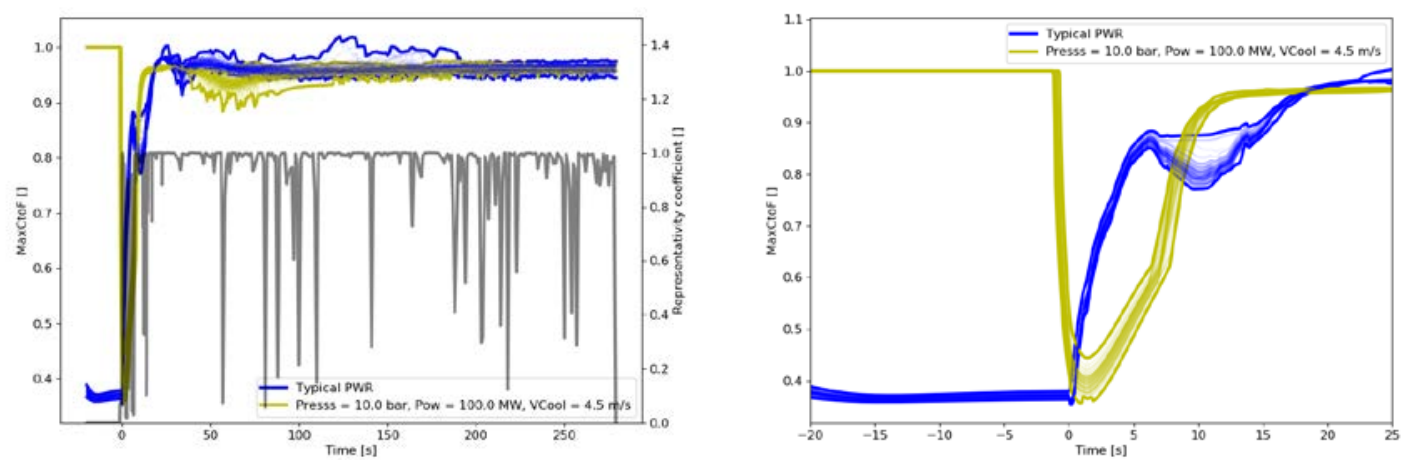

Figure 27. Maximum cladding to center line fuel temperature for 5-rod design, 10 bar back-up pressure, 100MW TREAT heating power and $4.5 \mathrm{~m} / \mathrm{s}$ coolant velocity. Left: 300 second transient with representativity on right side axis. Right: Zoom of first 25 seconds of transient.
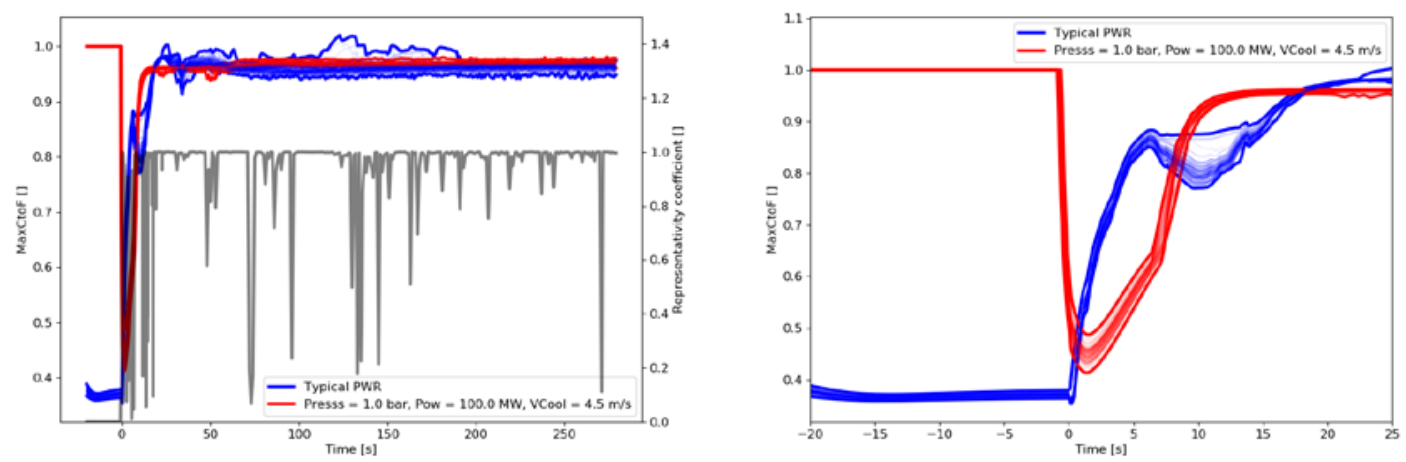

Figure 28. Maximum cladding to center line fuel temperature for 9-rod design, 1 bar back-up pressure, 100MW TREAT heating power and $4.5 \mathrm{~m} / \mathrm{s}$ coolant velocity. Left: 300 second transient with representativity on right side axis. Right: Zoom of first 25 seconds of transient.
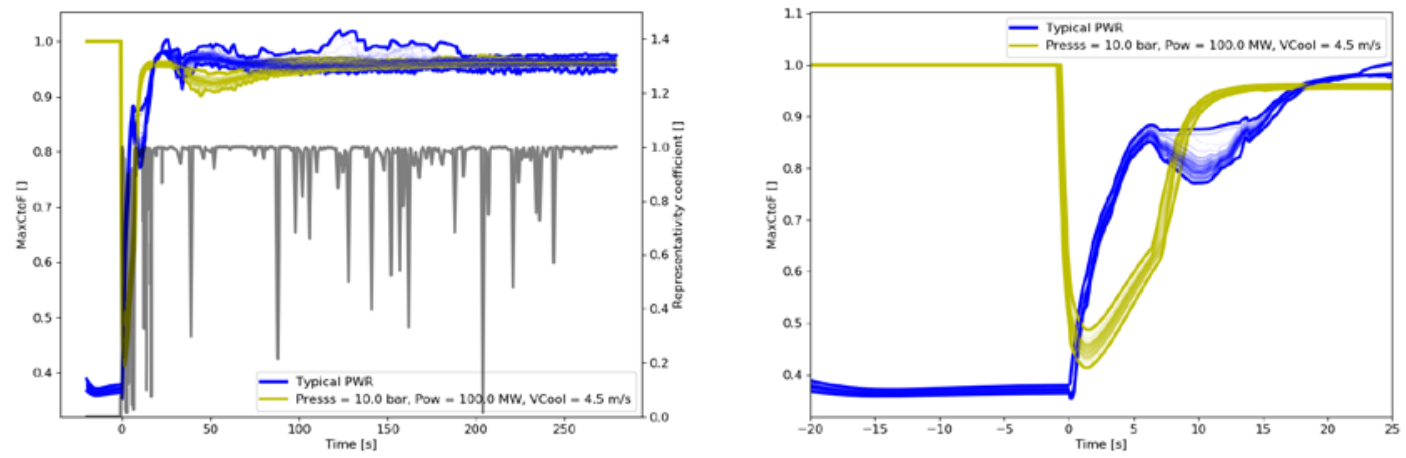

Figure 29. Maximum cladding to center line fuel temperature for 9-rod design, 10 bar back-up pressure, 100MW TREAT heating power and $4.5 \mathrm{~m} / \mathrm{s}$ coolant velocity. Left: 300 second transient with representativity on right side axis. Right: Zoom of first 25 seconds of transient. 


\subsubsection{Representativity and Prototypicality Conclusions}

With respect to the analyses of how "prototypic" (how close the figures of merit between the experiment and the PWR are) and how "representative" (how much error reduction can be achieved in the simulations with the gained information from the experiment) the TWERL experiment design is compared to a typical PWR, the following conclusions can be drawn:

- The overall transient behavior (prototypic) is as follows:

- The evolution of the pressure during the LOCA is well captured in TWERL for all experiment designs compared to the prototypic PWR.

- It has been shown that the coolant velocity and the TREAT power level to heat up the experiment fuel have limited impact on the transient behavior (PCT and MaxCtoF) for all test section designs.

- $\quad$ PCT

- $\quad$ The PCT is most influenced by the back-up pressure.

- $\quad$ Is can be seen that the short term behavior (first few seconds) of the transients is not much affected by the back-up pressure (depressurization phase). All test section designs show similar PCT behavior, i.e., somewhat under prediction of the first rise in temperature.

- $\quad$ The long term behavior (minutes) on the other hand shows significant differences with respect to the back-up pressure as well as the test section design. In general, the 1 bar back-up pressure cases overheat the fuel compared to the PWR while the 10 bar back-up pressure cases underheat the fuel in the long run of the transient (minutes). It seems there exists an intermediate back-up pressure that leads to most similar (prototypic) maximum PCT compared to the reference PWR.

- MaxCtoF

- $\quad$ The LOCA parameters investigated (back-up pressure, TREAT power, and coolant velocity) all have a limited impact on MaxCtoF.

- $\quad$ The 9-rod test section is the least prototypic for MaxCtoF.

- Considering the representativity, one can see that for all test section designs, the representativity is somewhat fluctuating between 0.0 and 1.0 at the beginning of the transient and then becoming very good (close to 1.0) for the rest of the transient. This indicates that the experiment design in general is very representative. However, the representativity (with respect to the uncertain parameters investigated) is not affected much by the number of rods in the test section. To tamper this conclusion, the following should be kept in mind:

- $\quad$ One clear limitation for applying the theory to the thermal-hydraulic field is the linearization of the transfer operator, i.e., the thermal-hydraulic behavior, which is known to be highly non-linear. Further work is needed to address this.

- It is worth bringing again to the reader's attention that the "representativity" index does not indicate how well or close a certain FOM is matched between the experiment model and the plant model, but shows how similar the FOM behaves under perturbations of the system and, consequently, how much uncertainty reduction can be achieved once experimental data become available for the model validation. All designs having similar representativity simply means that all considered designs will lead to a similar possibility for uncertainty reduction for the considered uncertain parameters (Coolant velocity in channel, Coolant inlet temperature, Power, Heat transfer coefficient and Rod pitch). 


\subsection{TWERL Pressure Drop Study}

After analyzing the "representativity" of TWERL with respect to a typical PWR, this section investigates the pressure drop in the loop for different test section configurations and heat exchanger designs. The size of these components will determine whether it is feasible for a "self-contained" loop (the whole assembly including pump, heat exchanger, and other components) to fit into the experiment opening in the TREAT reactor or whether the design has to be a "loop system concept."

\subsubsection{Boundary and Operating Conditions and Assumptions}

\subsubsection{Model Description}

The TWERL model used for this study is a simplified model from the "representativity" study. Simplifications compared to the model shown above in Figure 5 are:

- Fuel rod: No fuel rodlet is modeled. The loop pressure is investigated for different steady state fluid temperatures.

- Pump: The pump is modeled as a "Time Dependent Junction” in RELAP5-3D. This allows to easily impose a fluid velocity in the loop.

- Heat exchanger: Three different options for the heat exchanger have been explored. Detailed information of the different heat exchanger options can be found later.

\subsubsection{Parametric Studies}

In order to investigate the pressure drop in the loop for different conditions and designs, the following parametric studies have been performed.

\subsubsection{Test Section}

The same four test sections as for the "representativity” have been investigated (see Figure 6 and Table 2).

\subsubsection{Coolant Velocity and Temperature}

As mentioned, this simplified RELAP5-3D model of the TWERL loop addresses just the hydraulics. Therefore, steady state isothermal calculations were run. Considering the prototypical conditions from Table 3, the following temperatures and velocities have been run with the model:

- $\quad$ Test section fluid velocity: 4.9 and $5.3[\mathrm{~m} / \mathrm{s}]$.

- $\quad$ Test section fluid temperature: 540, 560, 580 and 600 [K].

Table 4 shows the resulting volumetric flows (same for all temperatures) and mass flows (for the 540K case) for the different test sections considered.

Table 4. Volumetric flow and mass flow for selected fluid velocities in the different TWERL test section designs.

\begin{tabular}{|l|l|l|l|l|}
\hline \multicolumn{1}{|c|}{ \# of rods } & \multicolumn{1}{|c|}{$\mathbf{1}$} & \multicolumn{1}{c|}{$\mathbf{4}$} & \multicolumn{1}{c|}{$\mathbf{5}$} & \multicolumn{1}{c|}{$\mathbf{9}$} \\
\hline Vol. flow [m3/s] v=4.9 & $5.186 \mathrm{E}-04$ & $2.156 \mathrm{E}-03$ & $2.528 \mathrm{E}-03$ & $4.699 \mathrm{E}-03$ \\
\hline Mass flow [kg/s] v=4.9 @540K & 0.408 & 1.695 & 1.988 & 3.694 \\
\hline Vol. flow [m3/s] v=5.3 & $5.609 \mathrm{E}-04$ & $2.332 \mathrm{E}-03$ & $2.734 \mathrm{E}-03$ & $5.082 \mathrm{E}-03$ \\
\hline Mass flow [kg/s] v=5.3 @540K & 0.441 & 1.834 & 2.150 & 3.996 \\
\hline
\end{tabular}




\subsubsection{Heat Exchanger Design}

To evacuate heat from the rods in the test section and keep thermal-hydraulic conditions (fluid inlet temperature) constant, a heat exchanger will most likely be included in the TWERL design. No heat exchanger for TWERL has been designed at the time of this writing. However, the pressure drop in such a heat exchanger might contribute significantly to the overall loop pressure drop. To estimate the contribution of a possible heat exchanger to the loop pressure drop, the following scenarios have been considered:

- No or concentric tube heat exchanger: This case considers either no heat exchanger or a heat exchanger that does not change the flow characteristics in the down-comer. This case assumes that the heat exchanger is made from one $\sim 2.5 \mathrm{~cm}$ diameter tube, same as the bend and down-comer.

- Simple tube and shell heat exchanger: To get an order of magnitude of the pressure drop of a possible TWERL heat exchanger, greatly simplified counter-current, staggered array, tube and shell heat exchangers have been dimensioned for the different test sections. To estimate the heat exchange area, the Log Mean Temperature Difference method (LMTD) has been used, invoking the Zukauskas correlation on the shell side and the Dittus-Boelter correlation on the tube side, to evaluate the overall heat exchange coefficient. Tube diameter has been assumed to be $0.5 \mathrm{~cm}$ while tube row pitch (SL) and tube pitch (ST) have both been assumed to be $1 \mathrm{~cm}$. The shell side inlet temperature has been assumed to be $300 \mathrm{~K}$ and the tube side inlet temperature 560K (prototypical PWR outlet temperature). The tube side mass flow rate has been assumed to be such that the temperature rise in the test section is $40 \mathrm{~K}$ (prototypical PWR temperature rise) while the shell side mass flow rate has been assumed to be the same as the tube side. It is worth noting that this flow rate is smaller than the flow rates considered for testing reported in Table 4. The heat exchanger is assumed to have 5 baffles. The number of tube rows as well as the number of tubes in one row (and consequently the heat exchanger length) have been optimized to find the smallest heat exchanger volume. To be able to achieve steady state temperature conditions, the heat exchangers must be dimensioned to evacuate the heat from all the rods in the test sections. To compute the power generated in the test section, a linear heat rate of $11 \mathrm{~kW} / \mathrm{ft}$ has been assumed (maximum linear heat rate observed in typical PWR under normal operating conditions). All the rods in the test section are assumed to be $4 \mathrm{ft}$ long. Table 5 shows the resulting heat exchanger designs for the different test section designs. It is worth mentioning that these heat exchanger designs are very rough and should only be considered for an order of magnitude estimation of the pressure drop. More detailed heat exchanger designs are needed that, in addition to listing all the design assumptions made here, also consider other technologies like, for example, compact-plate.

Table 5. Simple heat exchanger designs for the different TWERL test section designs.

\begin{tabular}{|l|l|l|l|l|}
\hline \multicolumn{1}{|c|}{ \# of rods } & $\mathbf{1}$ & $\mathbf{4}$ & $\mathbf{5}$ & \multicolumn{1}{c|}{$\mathbf{9}$} \\
\hline Power to be evacuated [kW] & 44 & 176 & 220 & 396 \\
\hline $\begin{array}{l}\text { Flow rate for core } \square \mathbf{T}=\mathbf{4 0 K} \\
\text { [kg/s] }\end{array}$ & 0.159 & 0.638 & 0.797 & 1.435 \\
\hline HX length $[\mathbf{m}]$ & 0.343 & 0.358 & 0.373 & 0.403 \\
\hline HX flow area $\left[\mathbf{m}^{2}\right]$ & $5.890 \mathrm{E}-04$ & $1.139 \mathrm{E}-03$ & $1.217 \mathrm{E}-03$ & $1.492 \mathrm{E}-03$ \\
\hline HX $\mathbf{D}_{\mathbf{h}}[\mathbf{m}]$ & 0.005 & 0.005 & 0.005 & 0.005 \\
\hline HV volume $\left[\mathbf{m}^{\mathbf{3}}\right]$ & $1.644 \mathrm{E}-03$ & $3.225 \mathrm{E}-03$ & $3.578 \mathrm{E}-03$ & $4.711 \mathrm{E}-03$ \\
\hline
\end{tabular}

- More pressure drop: To account for the large uncertainty in the heat exchanger design, a case where the tube length has been assumed to be 1.5 times the one computed in Table 5 has been considered. 
In the current RELAP5-3D model for TWERL, only the tube side of the heat exchanger has been modeled, since the primary interest is in the TWERL loop pressure drop and not the shell side of the heat exchanger. To fix the temperature of the fluid in the RELAP5 model, the outer surfaces of the heat exchanger tubes have been set to a constant temperature, and the heat transfer area multiplier in RELAP5 has been set to an arbitrary large number.

\subsubsection{Wall Roughness}

To assess the uncertainty of the loop pressure drop with respect to the wall roughness, a sensitivity study has been performed. The following wall roughnesses (applied to the whole loop, i.e., test section, heat exchanger, down-comer, etc.) have been considered:

- Wall roughness:1.52E-6 (drawn tubing), 1.5E-5 and 4.6E-5 (commercial steel) [m].

\subsubsection{Relap5 Model Scoping Results}

As mentioned, steady state isothermal calculations were run. All the sensitivities have been collected in six figures. Figure 30 and Figure 31 show the case of no heat exchanger, Figure 32 and Figure 33 the case with the simple tube and shell heat exchangers, and, finally, Figure 34 and Figure 35 show the case of "more pressure drop." The two figures for each case show the loop pressure drop as a function of the volumetric flow rate and the pump head as a function of the volumetric flow rate, respectively. Both, SI and imperial units are shown on all figures for the reader's convenience. The sensitivities for the different test section designs (number of rods) and wall frictions are plotted as different series with different colors in the plots. The eight points with the same color in each series represent the sensitivities to the two fluid velocities as well as the four different fluid temperatures. It is worth mentioning that for the figures presenting the pump heads, the sensitivity to the fluid temperature cannot be seen (the points are on top of each other), since the change in fluid density with temperature just compensates the difference in pressure drop.

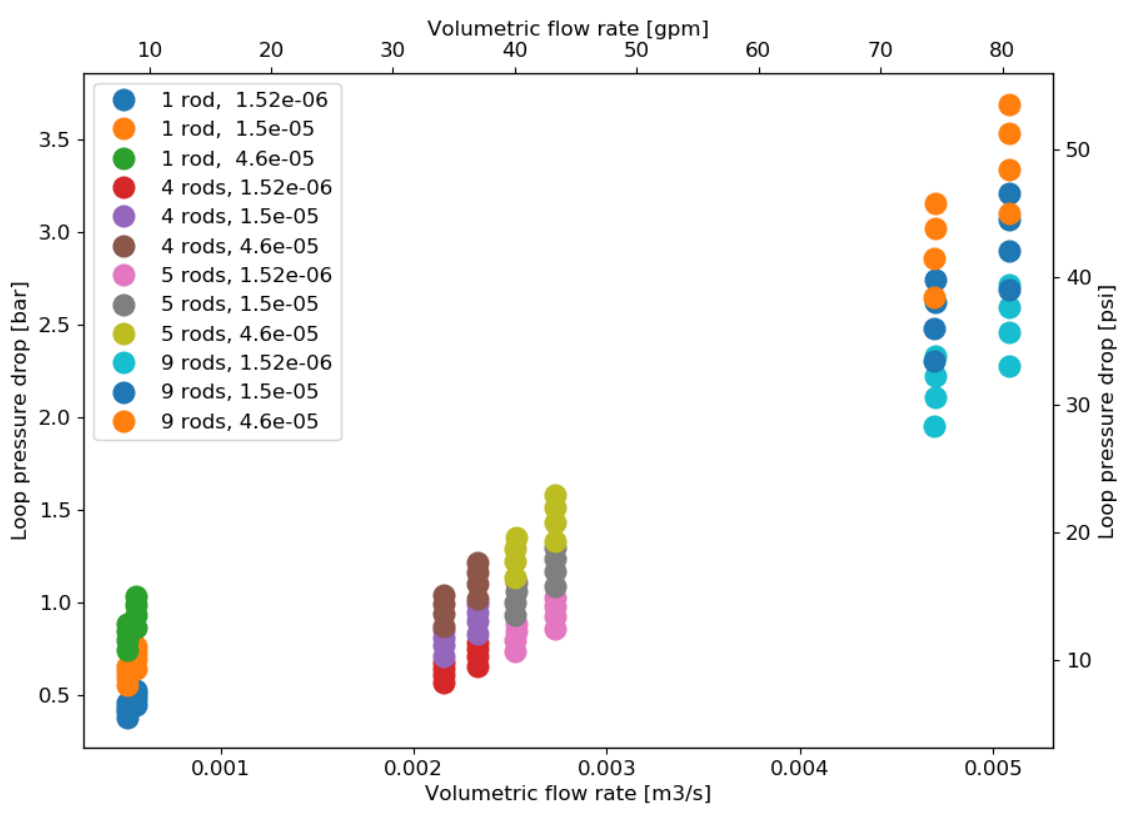

Figure 30. No heat exchanger, volumetric flow rate vs. loop pressure drop. 


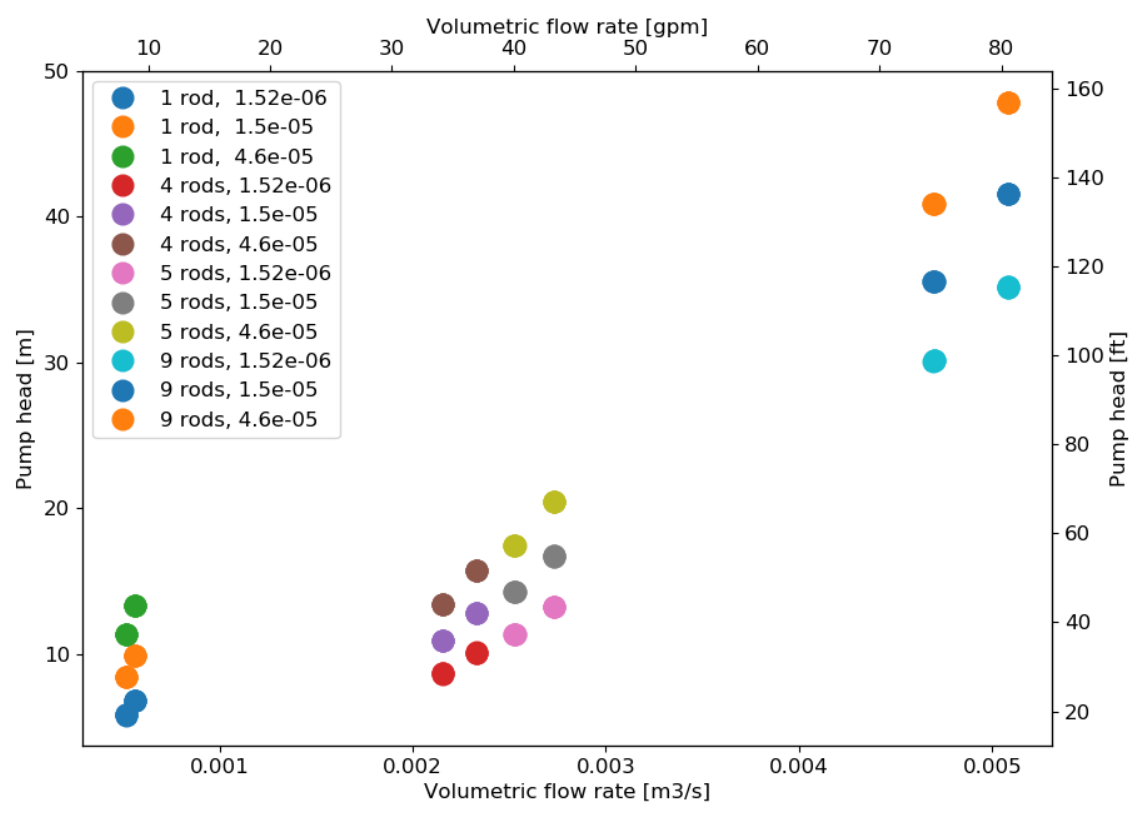

Figure 31. No heat exchanger, volumetric flow rate vs. pump head.

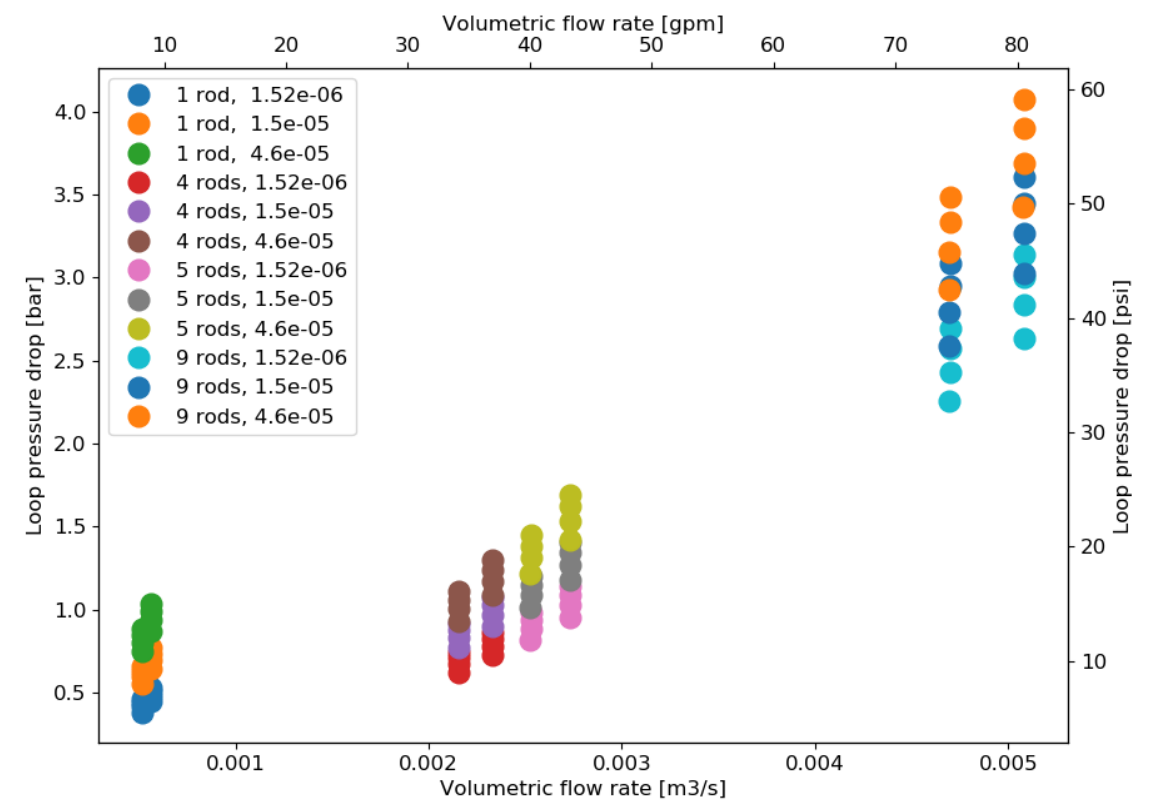

Figure 32. Simple heat exchanger, volumetric flow rate vs. loop pressure drop. 


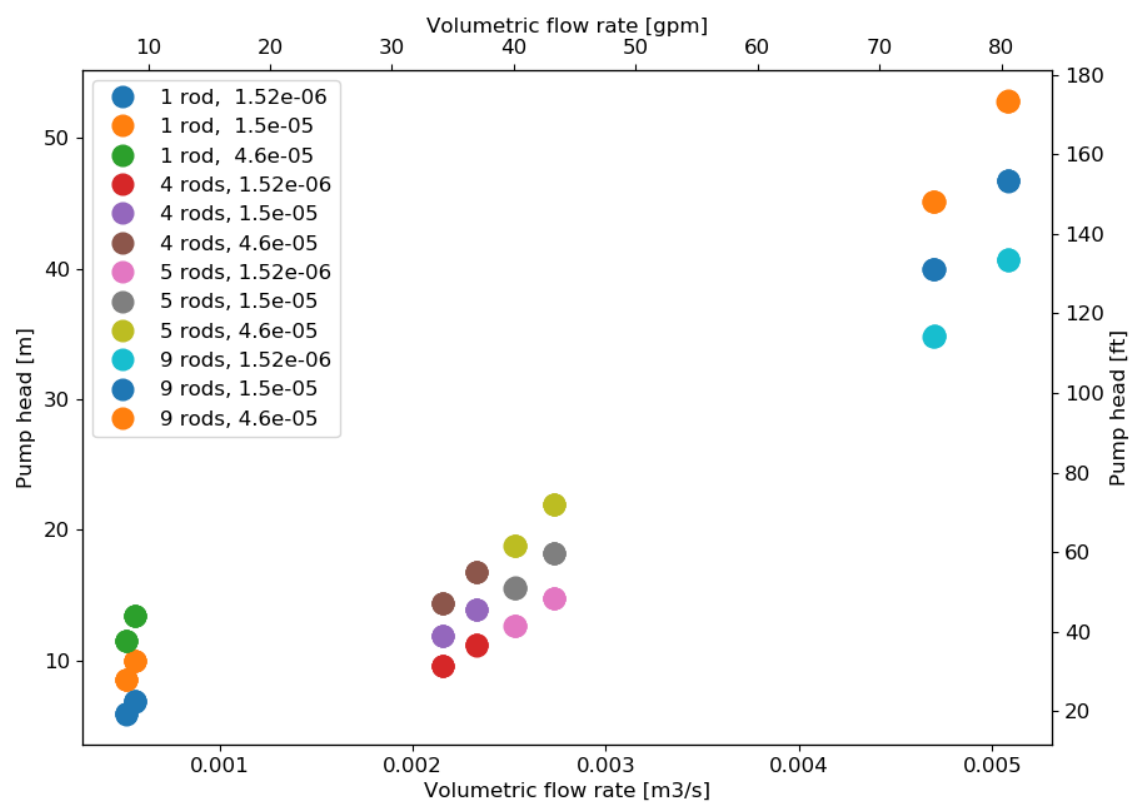

Figure 33. Simple heat exchanger, volumetric flow rate vs. pump head.

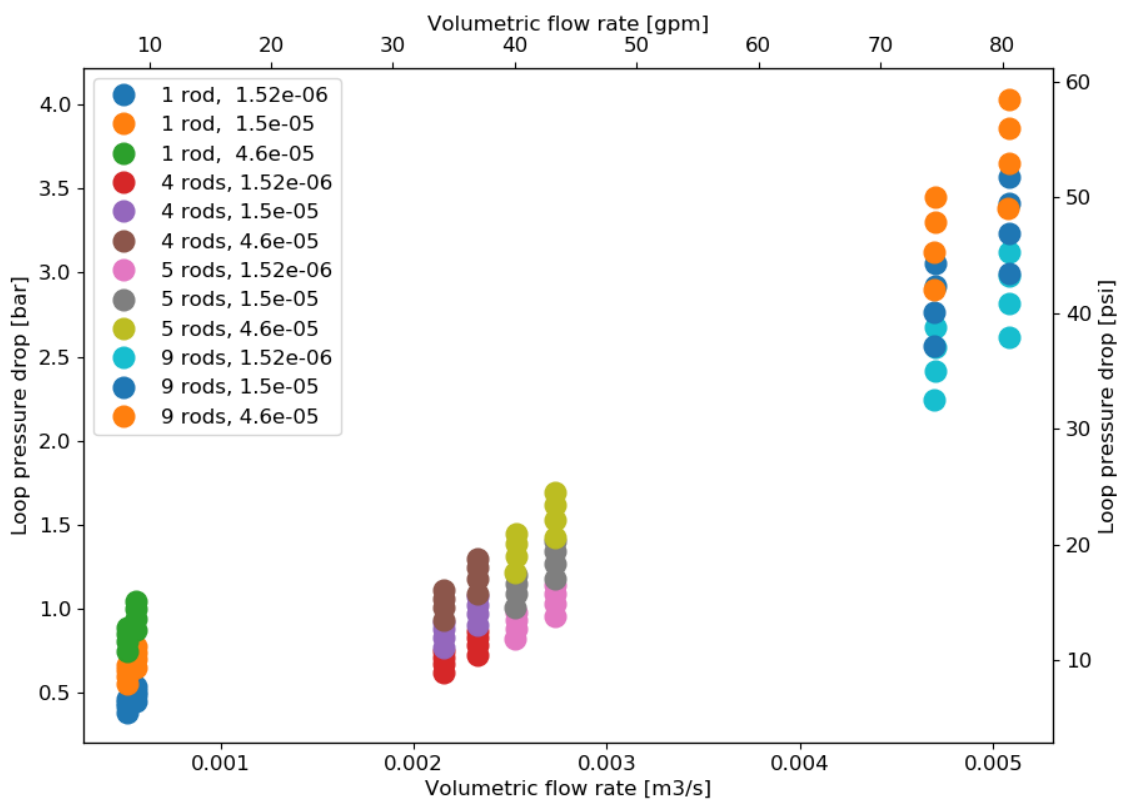

Figure 34. More heat exchanger pressure drop, volumetric flow rate vs. loop pressure drop. 


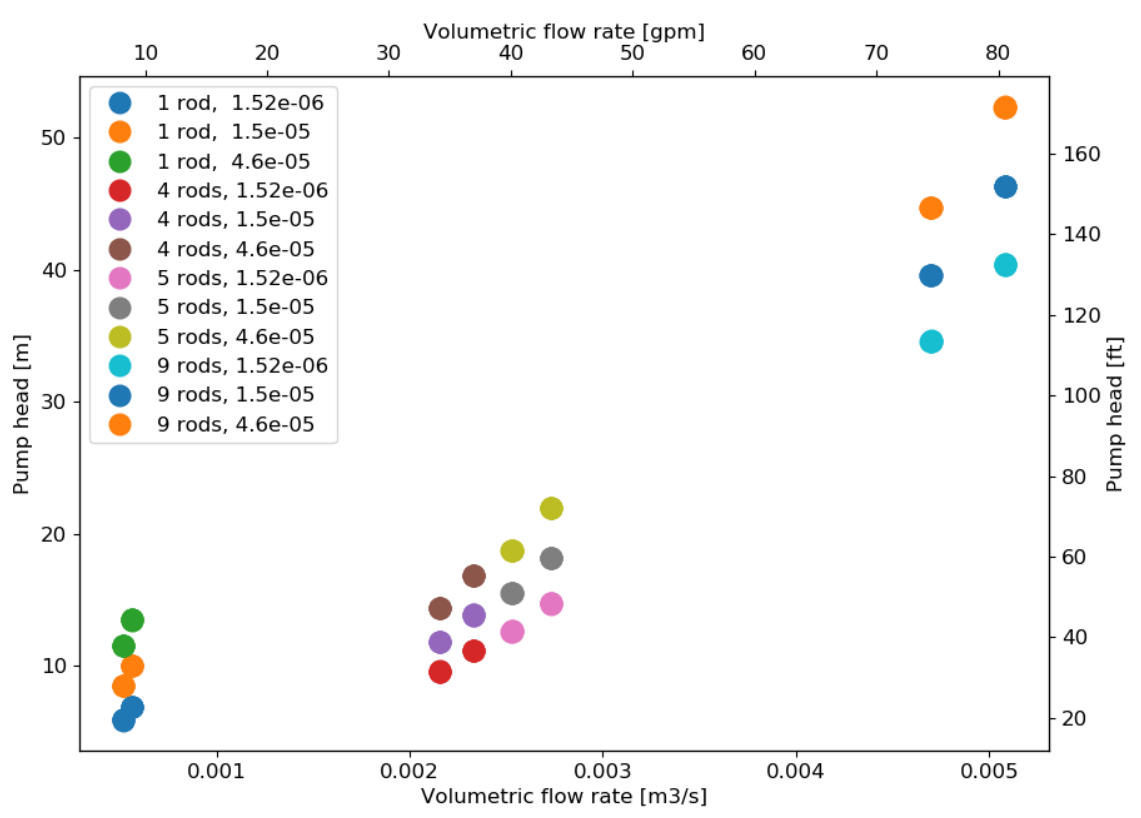

Figure 35. More heat exchanger pressure drop, volumetric flow rate vs. pump head.

\subsubsection{Pressure Drop Study Conclusions}

Concerning the pressure drop study, the main conclusions are:

- The model includes abrupt area changes and friction losses for tube bends. However, it does not include any pressure losses from instrumentation, flow distribution devices at the test section inlet, and other irregular features of the loop that will only be revealed during a more detailed design of the TWERL loop. These will likely increase the pressure loss in the loop.

- The simple tube and shell heat exchanger models used in this study show that the pressure drop from the heat exchanger does not influence the overall loop pressure drop much. The heat exchangers need to be properly designed to evaluate more accurately the pressure losses across them. Since small heat exchanger size is critical for the possibility of a self-contained loop design, compact-plate heat exchangers should be envisaged as well. Compared to the modeled shell and tube design, these will have a higher pressure drop.

- The 5-rod design needs a similar pump head than the smaller 4-rod design whereas the 9-rod bundle design needs a significantly higher pump head and mass flow rate. The pump heat for the 9-rod design could be lowered by making the down-comer pipe larger (the down-comer has the same diameter of all test section designs), but the flow rate will stay the same.

\subsection{Overall Conclusions}

The following overall conclusions for the TWERL LOCA transient can be drawn:

- All test sections are similarly prototypic with respect to PCT, while the 9-rod bundle test section is the least prototypic with respect to MaxCtoF (the 1, 4 and 5-rod sections are similar).

- $\quad$ The 4 and 5-rod test sections have similar pressure drops (i.e., will require similar pump sizes) while the 9-rod bundle leads to a significantly higher pressure drop. 
- The transient parameters investigated (back-up pressure, coolant velocity and TREAT power level) show that PCT and MaxCtoF behavior cover the range of uncertainty of the PWR simulations, i.e., it should be possible to find a combination of these parameters that leads to best prototypic PWR conditions.

- With respect to representativity, none of the investigated test sections stand out for both PCT and MaxCtoF. All test sections (and investigated transient parameters) behave similarly. All investigated test sections have a very good representativity, i.e., lead to a very good reduction in uncertainty for the investigated parameters.

- It is worth mentioning that a more complete set of uncertain parameters should be assembled, since the representativity might be different for different test sections for other uncertain parameters.

- In addition, other relevant physics (fuel performance) should be included in the simulation to be able to estimate the representativity for the most relevant figures of merit with respect to the TREAT main goal, i.e., fuel failure mechanisms.

The present scoping study shows that a 4 or 5-rod design will lead to most prototypic conditions easiest, i.e., by using boundary conditions that are close to the one in the typical PWR for a LOCA transient. Other relevant transients (reactivity induced accidents (RIA), etc.) should be investigated as well. The final decision on the test section design will depend on (with respect to thermal-hydraulics):

- The manufacturer's capability to provide a pump with the needed characteristics., ideally, one that will be able to drive 4 to 5 rods in the test section with coolant velocities $>4.5 \mathrm{~m} / \mathrm{s}$.

- The heat exchanger size (and associated pressure drop) needed for number of rods in the test section. The pump will have to be able to drive the flow considering the additional pressure drop generated by the heat exchanger.

- In the present study, the same PCF has been used for all test section designs. It needs to be clarified how many rods TREAT can neutronically drive and how the PCF changes with the number of rods. 


\section{PUMP DESIGN}

Based on the hydraulic predictions described above, a subcontract was undertaken with Hayward Tyler Inc., who had recently designed and fabricated custom high-pressure motor pumps for use at the INL Advanced Test Reactor (ATR). This larger pump developed for the ATR, or a similar off-the-shelf model, were assumed to be more than adequate for use in the facility-scale loop concept. Rather, this contract was based on providing a "paper-only" pump design with some reasonable level of engineering detail to demonstrate whether a suitably small pump could provide enough cooling for the self-contained TWERL layout (specifically the 5-rod bundle case). The requirements for this pump were provided in a contractual document and summarized below:

- $\quad$ The pump should be designed to provide equivalent protection to that afforded by the ASME Boiler and Pressure Vessel Code, Section III, Class 1.

- The pump, including inlet/outlet piping, fitting, terminal box, etc., will need to fit and operate inside an enclosure no greater than the envelope illustrated in Figure 36.
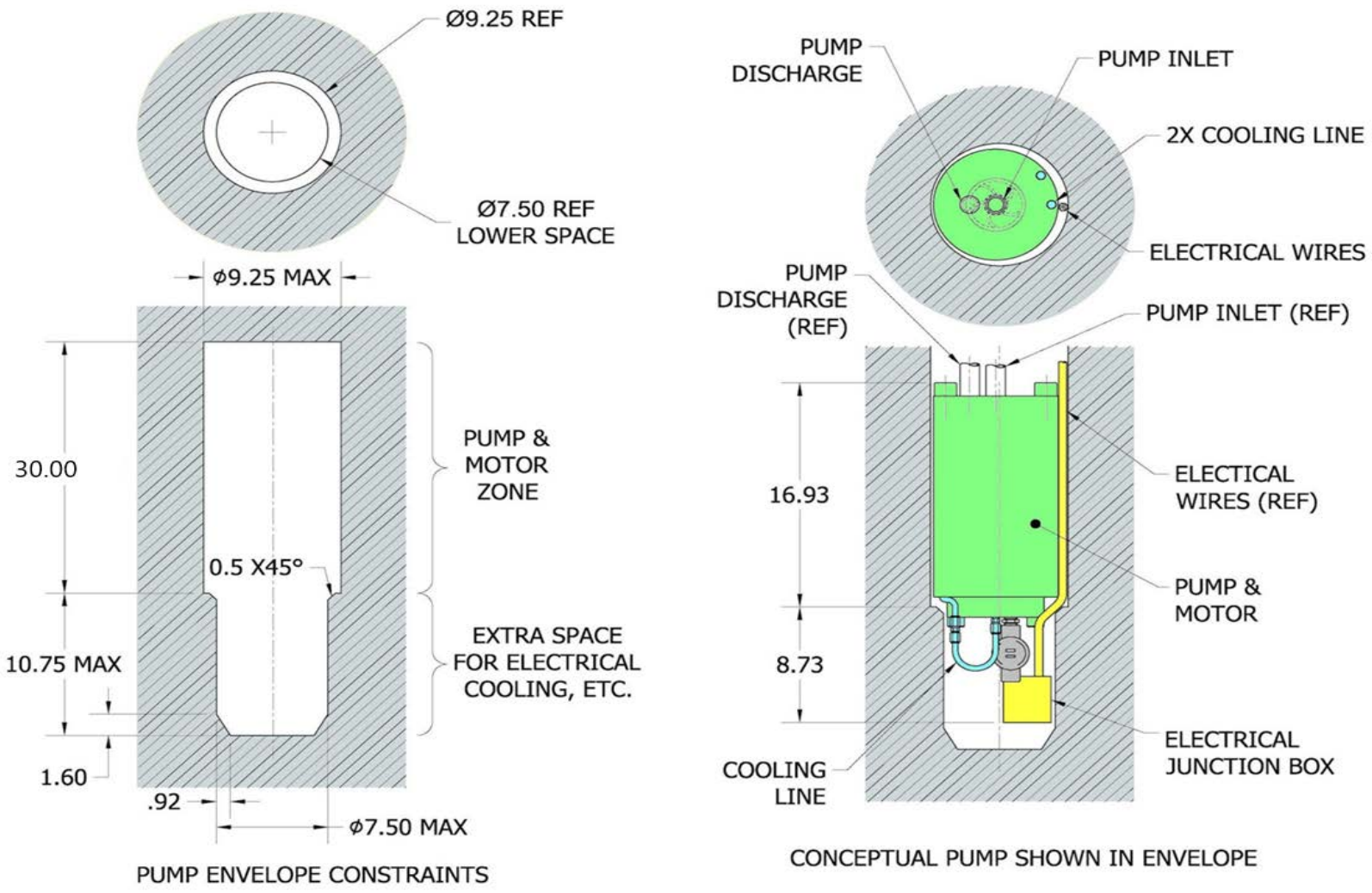

Figure 36. Pump Dimensional Envelope (dimensions in inches).

- The pump will need to withstand steady state pressure and temperature of the water being pumped at $16 \mathrm{MPa}$ and $300^{\circ} \mathrm{C}$, with the potential for brief excursions ( $<1$ minute), so that a design pressure and temperature of at least $21 \mathrm{MPa}$ and $370^{\circ} \mathrm{C}$ for the pump's pressure retaining components is needed.

- The pump will need to resist corrosion due to high temperature water, but the total pump service life will not likely exceed $250 \mathrm{hrs}$. The pump will not likely receive any maintenance during this period (i.e., bearing replacement, etc.) 
- The pump will need to tolerate up to 250 on/off cycles during its service life. It will not likely run continuously for any more than 10 hours.

- The wires and electrical components in the pump should be designed from materials with good stability in gamma radiation environments.

- The pump shall be designed so that any features which disengage the pump (circuit breakers, thermal cut-offs, etc.) can be reset remotely rather than by manual access to the pump unit.

- The pump will need to be extremely resistant to leakage of the water being pumped. The entire system, including the pump, shall pass a helium leak check not greater than $1 \times 10 \mathrm{E}-6$ standard $\mathrm{cm} 3 / \mathrm{s}$.

- The pump unit shall be able to operate inside an enclosure which is filled with inert gas with very little air flow to remove heat from the pump unit. Cooling water at $\sim 5$ gpm can be provided to the unit, but the cooling water cannot penetrate the primary pressure boundary so that it mixes with the water being pumped.

- The pump shall be able to run from $30 \%$ to its $100 \%$ of its capacity via variable frequency drive. The pump design should correspond with a recommended variable frequency drive (VFD) unit which can be controlled by an external data acquisition and control system.

- The pump and its VFD shall be able to provide the following hydraulic conditions:

- Case 1: Flowrate $0.0017 \mathrm{~m}^{3} / \mathrm{s}$ with a pump head of $18 \mathrm{~m}$

- Case 2: Flowrate $0.0023 \mathrm{~m}^{3} / \mathrm{s}$ with a pump head of $18 \mathrm{~m}$

- $\quad$ Case 3: Flowrate $0.0027 \mathrm{~m}^{3} / \mathrm{s}$ with a pump head of $20 \mathrm{~m}$.

At the time this report was written, the pump design supplier had not yet delivered their final report on their efforts due to a few-week misalignment in the deadlines for the present TWERL report and contracted deliverable date (at which point, detailed pump curves and a more comprehensive design documentation will be available). The contractor, however, provided a comprehensive update to the authors of this report in which their innovative approach was discussed. The innovative features of their design are predicted to meet all the above performance requirements, including as important the 5-rod flow case. This was accomplished within the challenging geometric envelope (which is limited by diameters of existing TREAT shipping casks) by using a multistage (two-impeller) design and integrating fluid discharge outlet into the impeller housing. The pump's motor is also cooled by an integrated water-cooling jacket which does not mix with the primary fluid. This approach allows pump cooling water to pass through the active core and to the pump in the grid-plate area without concern for radioactive contamination (apart from some short lived ${ }^{16} \mathrm{~N}$ activation) in the plumbing routed outside of the core's concrete shielding. This finding was a crucial development in evaluating the viability of the self-contained loop concept. Design renderings of the proposed pumps can be seen in Figure 37. 

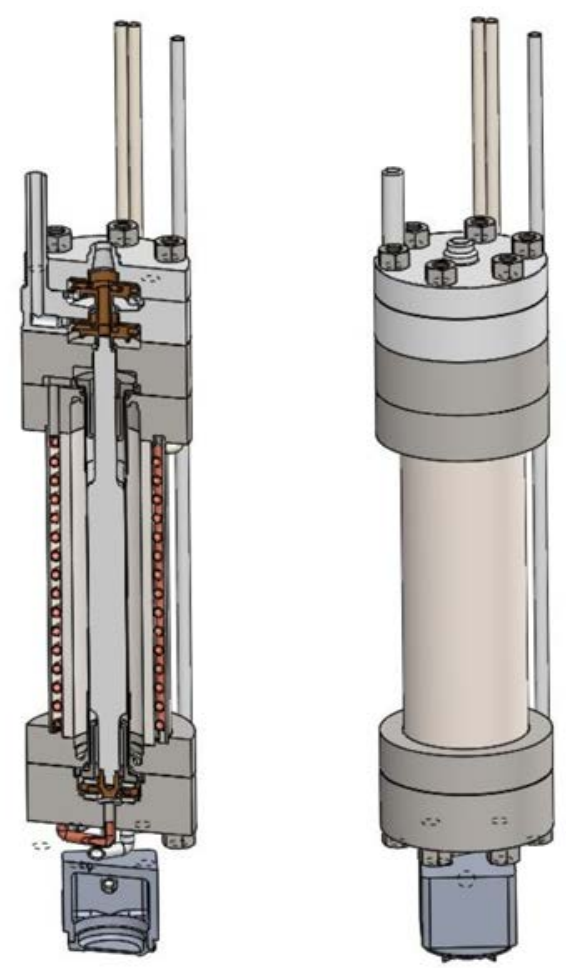

Figure 37. Preliminary Renderings of Compact Canned Motor Pump.

\section{CONCLUSIONS}

To order to support final selection of a TWERL concept and to support initiation of formal engineering in the future, an effort was undertaken to produce formal TWERL design input requirements. The full requirements are contained in reference [3]. Both TWERL layout concepts were evaluated in the context of these documented requirements and the new findings that resulted from efforts summarized in this report. Hydraulic modeling showed reasonable comparison between LWR plants and either of the candidate TWERL concept layouts, and showed that the central rod within a 5-rod X-shaped bundle would be within the hydraulic limitations of a compact pump. A supplier of custom water pumps provided high confidence in such a pump through design of a dual impeller canned motor pump having an integrated and isolated cooling jacket. Based on the design requirements developed for TWERL and the efforts described in this report, it was determined that the original selection of a compact self-contained loop remained valid and well placed for programmatic needs. The primary justification for this decision is the favorable balance between experiment thermal hydraulic capabilities and the cost of deploying a self contained loop design which, although it entails custom compact pump development, is expected to be far less than the radiologic hazard mitigation needed for the system-scale loop. Lastly, more than just reaffirming a prior decision, these efforts cultivated hydraulic models for accelerating future design efforts, identified design parameters able to affect a more capable system, and identified a viable supplier for the crucial compact water pump. 


\section{REFERENCES}

1. “TREAT Water Loop Status Report,” INL Report INL/LTD 1536768 FCRD-FUEL-2015-000778, September 2015.

2. “Scoping Studies to Determine TREAT's Capabilities for Testing PWR Multi-Rod Bundles,” INL Report INL/INT-16-37910, February 2016.

3. INL Document FOR-480, “TWERL Irradiation Device for TREAT,” rev 0, 8/28/19. 